\title{
EN TORNO AL CONCEPTO JURÍDICO DE AUTOPROVISIÓN ADMINISTRATIVA: DIMENSIÓN EUROPEA Y DESAJUSTES INTERNOS ${ }^{1}$
}

\author{
CARLOS-ALBERTO AMOEDO-SOUTO \\ Universidade da Coruña \\ casou@udc.gal
}

Cómo citar/Citation
Amoedo-Souto, C.-A. (2018).
En torno al concepto jurídico de autoprovisión administrativa:
dimensión europea y desajustes internos.
Revista de Administración Pública, 205, 81-129.
doi: https://doi.org/10.18042/cepc/rap.205.03

Resumen

El presente trabajo constituye una defensa del concepto jurídico de autoprovisión administrativa como conjunto de reglas que atienden a la satisfacción preferente de las necesidades administrativas con los medios, bienes y servicios proporcionados por el sector público. Este concepto ofrece las ventajas de: a) integrar estratégicamente las distintas posibilidades de cooperación horizontal (convenios interadministrativos) y vertical (encargos a medios propios), tal y como se han acuñado por las directivas comunitarias de contratación de 2014 ; b) ordenar de manera más sistemática, clara e inteligible el derecho administrativo español, aquejado de múltiples desajustes, en especial como consecuencia de la aprobación de la Ley 9/2017. El trabajo concluye con la propuesta de aprobación de una ley básica especial de autoprovisión para el conjunto del sector público español.

1 Trabajo elaborado en el marco del proyecto de investigación «El impacto de la crisis de gasto público en las técnicas jurídicas de contratación pública», 2016, Axencia Galega da Innovación, (código 2010.PXI.2421). En el momento de cierre del trabajo, el Proyecto de Ley sobre procedimientos de contratación en los sectores del agua, la energía, los transportes y los servicios postales por la que se transpone al ordenamiento jurídico español la Directiva 2014/25/UE, del Parlamento Europeo y del Consejo, de 26 de febrero de 2014 permanece encallado en la Comisión de Hacienda del Congreso de los Diputados. 


\title{
Palabras clave
}

Autoprovisión; colaboración público-público; directivas comunitarias de contratación; Ley de Contratos del Sector Público.

\begin{abstract}
This paper stands for a new legal concept of in-house providing, as the set of rules about make or buy decisions to be taken in order to meeting the administrative needs with goods, services and utilities provided by the public sector. This notion grants two main assets: a) bringing together the procedures of public-public cooperation (both vertical and horizontal) within the public sector, as set out in the 24 and 23 Directives on public procurement (2014); b) arrange in a more properly and clear way the Administrative Law of Spain, seriously concerned by several misalignements, specially those dealing with the brand new rules stated by the 9/2017 Public Procurement Act. Our work ends with a lege ferenda proposal: the need of passing a special law about in house providing for the hole spanish public sector.
\end{abstract}

\section{Keywords}

In house providing; Public-public cooperation; Directives on public procurement; spanish Act on Public Procurement. 


\section{SUMARIO}

I. AUTOPROVISIÓN ADMINISTRATIVA: LA NECESIDAD DE UN NUEVO CONCEPTO JURÍDICO. II. LOS FUNDAMENTOS COMUNITARIOS DE LA AUTOPROVISIÓN: 1. Teckal, o el hilo de Ariadna de la provisión. 2. El nuevo planteamiento de las Directivas de contratación de 2014. 3. Autoprovisión, mercado y competencia. III. LOS DESAJUSTES ESTRUCTURALES DEL DERECHO PÚBLICO ESPAÑOL: 1. La autoprovisión, entre la lógica de la sospecha y un uso generalizado. 2. La autoprovisión, entre organización, técnica de gestión y libre concurrencia: 2.1. La faceta operativa. 2.2. La faceta concurrencial. 2.3. La perspectiva organizativa. IV. LOS NUEVOS DESAJUSTES DE LA LEY 9/2017, DE 8 DE NOVIEMBRE, DE CONTRATOS DEL SECTOR PÚBLICO: 1. Encomiendas de gestión, convenios, encargos: dentro y fuera. 2. La participación privada en las personificaciones instrumentales: geometría variable. 3 . El distinto régimen de recurso especial. 4. La hipertrofia del antiguo 24.6 TRLCSP: artículos 31 a 33 Ley 9/2017. 5. La enigmática regulación de la gestión de servicios públicos mediante personificaciones instrumentales. V. LA POSITIVACIÓN DE LA AUTOPROVISIÓN ADMINISTRATIVA EN EL DERECHO AUTONÓMICO DE GALICIA. VI. PROPUESTA DE LEGE FERENDA.

\section{AUTOPROVISIÓN ADMINISTRATIVA: LA NECESIDAD DE UN NUEVO CONCEPTO JURÍDICO}

El presente trabajo es una primera aproximación a la construcción de un concepto jurídico de autoprovisión administrativa en el derecho español.

Aunque algunos autores utilizan el concepto de autoprovisión como la mejor traducción de la contratación o encargos in house providing ${ }^{2}$, el concepto que vamos a defender aquí es más amplio.

2 En este sentido, cfr. M. Vilalta Reixach y B. Pérez Bernabéu (2014), «Los llamados contratos de auto-provisión (o contratos in house providing)", en M. Yzquierdo Tolsada, J. M. Almudí Cid y M. A. Martínez Lago (coords.), Contratos civiles, mercantiles, públicos, laborales e internacionales, con sus implicaciones tributarias, tomo 14, págs. 941 y ss. 
Con esa amplitud, se trata de proporcionar un paraguas conceptual al conjunto de técnicas excepcionadas de la aplicación de las directivas de contratación pública, mediante las cuales las administraciones públicas europeas pueden satisfacer las necesidades vinculadas al cumplimiento de sus misiones de servicio público sin terciarizar o acudir al mercado, es decir, sin demandar al sector privado la provisión de sus bienes y servicios.

Fundamentalmente, se trata aquí de reencuadrar en nuestro derecho interno lo que la Comisión Europea ha denominado cooperacion públicopúblico horizontal no institucionalizada (fundamentalmente, convenios de colaboración interadministrativa) y cooperación vertical (los negocios in house providing). Terminología ya trasladada a las directivas de contratación de 2014 y, recientemente, a la nueva Ley 9/2017, de 8 de noviembre, de Contratos del Sector Público.

El supraconcepto de autoprovisión administrativa ha sido ya utilizado por algún legislador autónomico (en concreto, el gallego), considerándola como la primera opción del gestor público, antes de proceder a su terciarización al mercado mediante compra pública. Más allá del acierto y oportunidad de esta regulación autonómica, defendemos la necesidad de introducir una regulación básica común que, a partir de este supraconcepto, permita reordenar técnicamente nuestro derecho en este punto de una manera mucho más eficaz y clara que lo logrado hasta ahora por el legislador español, alineándolo de manera más consistente con el derecho común europeo ante la proliferación del uso de las técnicas de autoprovisión en la actual coyuntura postcrisis.

En esa conyuntura, se hace necesario conjurar en la medida de lo posible la particular «lógica de la sospecha» que sigue predominando en la comprensión jurídica de estas técnicas como subterfugios para huir del derecho administrativo $^{3}$ o para alterar la libre concurrencia mercantil. Tal lógica de la sospecha, me temo, es la causa de la criticable regulación «eficientista» de los medios propios estatales que se contiene en el art. 86 de la Ley 40/2015, regulación que incluso se ha atrevido a considerar la gestión indirecta contractual como primera opción frente a la gestión directa ${ }^{4}$, en una visión neoliberalizante

3 Desde el punto de vista de la "huida del Derecho Administrativo" hacia unos esquemas de funcionamiento administrativo menos garantistas y transparentes $\mathrm{y}$, por ende, más abiertos a las frecuentes patologías de nuestras administraciones (clientelismo, precarización laboral, corrupción, etc.). Véanse C. A. Amoedo Souto (2004), Tragsa. Medios propios y huida del Derecho Administrativo, Barcelona: Atelier; M. E. Cuadros Garrido (2014), "Patologías en el empleo público: el caso Tragsa», Nueva revista española de derecho del trabajo, 168, págs. 305-334.

4 De ello ha dado cuenta crítica J. Bermúdez Sánchez en su trabajo (2015) «La modificación de los modos de gestión de servicios públicos en el Proyecto de Ley de régimen 
y pancontractualista de la acción administrativa que, lejos de ajustarse a un requerimiento europeo, no es sino la enésima expresión de ese fenómeno tan característico del capitalismo espańol moderno que es la captura privada de rentas públicas.

Frente a ello, considero que las técnicas de autoprovisión deben ser vistas con naturalidad como una opción normal, incluso preferente y más racional en términos de eficiencia. Si el sector público es capaz de suministrarse entre sí bienes, realizar obras o prestar servicios de calidad a más bajo coste que el mercado, parece lógico que debamos regular su utilización y trazabilidad con toda la precisión posible, canalizando jurídicamente todo su potencial, que no es poco.

Tal estrategia jurídico-dogmática se orienta también a dar una respuesta lo más segura y garantista posible a aquellos enfoques políticos que, desde distintos fundamentos ideológicos, priorizan la satisfacción de las necesidades públicas dentro del sector público, y no desde la concurrencia de mercado: una discusión transeuropea en liza, que en España ha sido abanderada desde 2015 bajo el blasón de la remunicipalización de servicios ${ }^{5}$. Pero el «retorno» desde una gestión indirecta a otra directa no es, a día de hoy, ante el número de obstáculos legales existentes, ni la única ni probablemente la más satisfactoria de las soluciones ${ }^{6}$.

Situados en esa visión estratégica de la gestión administrativa en el actual contexto jurídico comunitario, político y presupuestario, el concepto de autoprovisión administrativa que voy a defender aquí trataría de regular el aprovechamiento eficiente de los recursos o servicios que puede prestar el

jurídico del sector público», Documentación Administrativa, 2, enero-diciembre, disponible en línea.

5 Sobre la remunicipalización desarrollada en España a partir de mayo de 2015, véanse los números 58-59 (febrero-marzo de 2016, Remunicipalización I) y 69 (mayo 2017, Remunicipalización II) del Cronista del Estado Social y Democrático de Derecho, en especial, de este último número, el trabajo de J. Esteve Pardo, «El movimiento remunicipalizador. Experiencias y expectativas», págs. 4-11. De sumo interés también resulta la monografía de A. Todolí Signes y D. Martínez Saldaña (2017), Remunicipalización de servicios, sucesión de empresa y trabajadores indefinidos no fijos, Cizur Menor: Thomson Reuters Aranzadi.

6 Véase T. Font i Llovet y J. J. Díez Sánchez (coords.), Los servicios públicos locales. Remunicipalización y nivel óptimo de gestión. Actas del XXI Congreso de la Asociación Italo-española de profesores de Derecho Administrativo, Madrid: Iustel-Fundación Democracia y Gobierno Local. En particular, mi comunicación (2017) «La autoprovisión administrativa como fórmula alternativa a la externalización contractual de servicios», págs. 117-130. 
conjunto de entidades instrumentales del sector público, antes de optar por la externalización contractual a terceros. De este modo, la regla de oro para el gestor público sería: «no contrates con una empresa lo que te pueda hacer de manera más eficiente una organización pública».

Esta propuesta hace de la autoprovisión la primera opción del gestor, incluyendo en ella el public outsourcing como second best en caso de insuficiencia de medios de la propia administración. Solo en caso de que la externalización pública, en sus distintas modalidades (horizontal o vertical), no satisfaga en el caso concreto los criterios legales de racionalidad, eficiencia y buena administración, se podría acudir a la externalización contractual privada, es decir, al mercado. La autoprovisión dejaría de ser una opción técnica más, y su uso se convertiría en preferente, invirtiendo así el dogma (neoliberal) del «contratista interpuesto». Ello supondría superar la actual visión de las técnicas de autoprovisión como algo excepcional ${ }^{7}$, y en particular la opción prioritaria por la externalización que, de modo anacrónico, se contiene en el art. 86 de la Ley 40/2015, ahora elevado a norma supletoria básica de todo el sector público por la disposición final cuarta de la Ley 9/2017.

\section{LOS FUNDAMENTOS COMUNITARIOS DE LA AUTOPROVISIÓN}

\section{TECKAL, O EL HILO DE ARIADNA DE LA AUTOPROVISIÓN}

El derecho comunitario nunca ha pretendido someter la satisfacción de toda necesidad pública a su externalización contractual en régimen de mercado. La razón es sencilla: los tratados constitutivos no autorizan expresamente a ello.

$\mathrm{Al}$ contrario, los Estados miembros han procurado salvaguardar a lo largo de los ańos —explícitamente, a partir del Tratado de Lisboa de 2007-un margen interno de decisión sobre cómo satisfacer las necesidades públicas, es decir, un margen sobre sus opciones de autoorganización administrativa, en especial respecto de los servicios públicos de interés general ${ }^{8}$.

7 Véase, por ejemplo, la Circular 4/2015, de 20 de mayo, de la Intervención General del Estado, sobre diversos aspectos relacionados con las encomiendas de gestión reguladas en los arts. 4.1.n) y 24.6 del TRLCSP, pág. 36.

8 Véase el art. 14 del TFUE, incluido por el Tratado de Lisboa de 2007, y muy especialmente su Protocolo 26, sobre los servicios de interés general, cuyo contenido conviene recordar: "Las altas partes contratantes, deseando enfatizar la importancia de los servicios de interés general, HAN CONVENIDO en las siguientes disposiciones interpretativas, que se incorporarán como anexo al Tratado de la Unión Europea y al Tratado de Funcionamiento de la Unión Europea: 
Puede afirmarse que la economía social de mercado sigue siendo el marco de política económica generalmente compartido por todos los países europeos. Pero es cierto, sin embargo, que el margen interno de los Estados ha ido reduciéndose a medida que se han ensanchado la latitud y profundidad de las políticas comunitarizadas exclusivas o compartidas de la Unión y, en especial, a medida que a lo largo de los años se ha intensificado la implantación de mecanismos ordoliberales de funcionamiento del mercado único. La Comisión Europea y el Tribunal de Justicia han adoptado un papel activo en tal sentido.

Precisamente por ello, la historia de la autoprovisión administrativa en Europa es la historia de la tensión entre el mantenimiento de ese margen soberano de autoorganización interna y el proceso de liberalización de servicios, promoción de la competencia y armonización de los procedimientos de adjudicación de contratos públicos.

Los procedimientos de armonización de la adjudicación de contratos públicos plasmados en las sucesivas directivas han venido reconociendo con mayor o menor alcance esta dialéctica. De hecho, la famosa doctrina sobre las excepciones in house providing que se acuña en el célebre asunto Teckal de 1999 (sentencia de 18 de noviembre de 1999, asunto C-107/98) nace de la distinta formulación de las excepciones previstas en las directivas de armonización de los procedimientos de adjudicación de contratos de servicios (1992) y suministros (1993) .

Artículo 1

Los valores comunes de la Unión con respecto a los servicios de interés económico general con arreglo al artículo 14 del Tratado de Funcionamiento de la Unión Europea incluyen en particular:

- El papel esencial y la amplia capacidad de discreción de las autoridades nacionales, regionales y locales para prestar, encargar y organizar los servicios de interés económico general lo más cercanos posible a las necesidades de los usuarios.

- La diversidad de los servicios de interés económico general y la disparidad de las necesidades y preferencias de los usuarios que pueden resultar de las diferentes situaciones geográficas, sociales y culturales.

- Un alto nivel de calidad, seguridad y accesibilidad económica, la igualdad de trato y la promoción del acceso universal y de los derechos de los usuarios.

Artículo 2

Las disposiciones de los Tratados no afectarán en modo alguno a la competencia de los Estados miembros para prestar, encargar y organizar servicios de interés general que no tengan carácter económico».

9 La excepción habitualmente utilizada era la prevista en el art. 6 de la Directiva 92/50, de servicios: «La presente Directiva no se aplicará a los contratos públicos 
$\mathrm{Al}$ encontrar su ratio decidendi en una interpretación engañosamente «objetiva» de la noción de contrato - pues, en realidad, sus dos famosos criterios, el control análogo y la realización de la parte esencial de la actividad, no son sino una mezcolanza de criterios subjetivo-organizativos y funcionales- este leading case cortó la cinta inaugural de un período de quince años de interpretación pretoriana de los derechos internos que giró en torno a los límites de compatibilidad entre la lógica concurrencial del mercado interior y las potestades de autoorganización interna de los servicios públicos de los Estados miembros. A pesar de que tales límites fueron resituados en las directivas de 2004, lo cierto es que el Tribunal de Justicia no ha dejado durante los últimos quince años de enriquecer su propia teorización, alumbrada en 1999, a partir de las múltiples cuestiones prejudiciales planteadas desde los tribunales administrativos nacionales, especialmente italianos, españoles y alemanes, en los que las fórmulas de colaboración entre niveles estatales, regionales y locales son tan cotidianas como variadas.

Del cúmulo de todas estas cuestiones prejudiciales se ha derivado una clara limitación de las potestades de autoorganización en virtud de la utilización de parámetros funcionales de control de los negocios jurídicos evaluados que han tratado de responder en cada caso a la pregunta de si el concreto negocio suponía una manifestación lícita de la potestad autoorganizatoria dirigida a la consecución de los fines de interés general propios de la Administración, o bien un negocio falseador de la libre concurrencia característica de la compra pública comunitaria. Lo cual ha obligado a replantear la gestión

de servicios adjudicados a una entidad que sea, a su vez, una entidad adjudicadora con arreglo a la letra b) del artículo 1 , sobre la base de un derecho exclusivo del que goce en virtud de disposiciones legales, reglamentarias y administrativas publicadas, siempre que dichas disposiciones sean compatibles con el Tratado». Este precepto pasó con alteraciones mínimas al art. 18 de la nueva Directiva 2004/18/ CE del Parlamento Europeo y el Consejo, de 31 de marzo de 2004, sobre la coordinación de los procedimientos de adjudicación de contratos públicos de obras, de suministro y de servicios, dedicadas a "contratos de servicios adjudicados en base a un derecho exclusivo». En la Directiva de sectores excluidos (93/38), las excepciones se contenían en el art. 13: empresas asociadas a la entidad adjudicadora, y cuando «una empresa conjunta, constituida por varias entidades contratantes con el fin de desarrollar las actividades contempladas en el apartado 2 del artículo 2, celebre con una de dichas entidades contratantes o con una empresa asociada a una de estas entidades contratantes, siempre que como mínimo el $80 \%$ del promedio del volumen de negocios que tal empresa haya efectuado en la Comunidad en los últimos tres años en materia de servicios provenga de la prestación de estos servicios a las empresas con las que esté asociada». 
de múltiples servicios, en especial locales, para evaluar su compatibilidad con esta jurisprudencia comunitaria ${ }^{10}$.

El corpus jurisprudencial generado en los últimos quince años ${ }^{11}$ podría caracterizarse de manera muy sumaria, por lo que ahora nos interesa, mediante tres rasgos distintivos:

- Su casuismo y heterogeneidad: el tribunal interpreta la compatibilidad de un concreto derecho "operativo" nacional con las directivas de contratación vigentes a la luz de casos concretos. La proliferación de asuntos sometidos a la jurisdicción del TJUE ha configurado un dédalo casuístico de jurisprudencia no siempre clara ni unívoca en su alcance, dadas las muchas particularidades que nacen de la coexistencia de 28 derechos administrativos nacionales distintos entre sí, y de las dificultades de traducción de sus avatares «patológicos» a las claves del derecho interno de otro Estado miembro ${ }^{12}$.

- Una visión pancontractualista de la actividad administrativa - y de la definición misma de la noción europea de contrato público — cristalizada mediante la profundización casuística en los dos requisitos generales de la aplicabilidad de la autoprovisión o in house providing: un criterio subjetivo-organizativo (la existencia de "control análogo») y otro criterio

10 Véase en particular el análisis comparado de K. Wauters (2015), Cooperative agreements between publico authorities. The influence of CJEU case law on national legal systems, Cambridge: Intersentia Publishing.

11 Los principales hitos de esta evolución han sido las sentencias del Tribunal de Justicia de 11 de enero de 2005, asunto Stadt Halle RPL Lochau (asunto C-26/03); de 13 de octubre de 2005, asunto Parking Brixen (C458/03); de 21 de julio de 2005, asunto Coname (C-231/03); de 19 de abril de 2007, asunto Tragsa (C-295/05); sentencia de 13 de noviembre de 2008, asunto Coditel Brabant (C324/07); de 9 de junio de 2009, asunto Hamburgo (C-480/06); sentencia de 10 de septiembre de 2009, asunto Sea Srll Commune di Ponte Nossa (C573/07); de 29 de noviembre de 2012, asunto Econord Spa; de 19 de diciembre de 2012, asunto Ordine degli Ingegneri della Provincia di Lecce (C-159/11); de 13 de junio de 2013, asunto Piepenbrock Dienstleistungen GmbH (C-386/11); Sentencia de 8 de mayo de 2014, asunto Datenlotsen Informationssysteme GmbH (C-15/13); Sentencia de 19 de junio de 2014, asunto Centro hospitalar de Setúbal y Such (C-574/12); Sentencia de 11 de diciembre de 2014, asunto Azienda sanitaria locale (C-113/13); Sentencia de 8 de diciembre de 2016, asunto Cogesa SpA (C-553/2015).

12 Cfr., en este sentido, el trabajo de S. de la Sierra Morón (2016), «Límites y utilidades del derecho comparado en el derecho público. En particular, el tratamiento jurídico de la crisis económico-financiera", Revista de Administración Pública, 201, págs. 6999. 
funcional (que la misión dominante de la entidad adjudicataria sea servir a su entidad controladora, sin una vocación predominante de operar en el mercado) relacionado con la salvaguarda de una limpia concurrencia mercantil entre sector público empresarial y sector privado.

- La progresiva dulcificación de una interpretación estricta de estos criterios. Tendencia que tiene su cabo de las tormentas en un asunto español: el caso TRAGSA II de 19 de abril de $2007^{13}$.

Por la concurrencia de estos tres rasgos, los últimos quince años han sido de una profunda inseguridad sobre la consistencia comunitaria de dos grandes aspectos o dimensiones de nuestro derecho administrativo en sus tres niveles territoriales: las formas organizativas (políticas de personificación instrumental) y las formas operativas (políticas de gestión pública a través de convenios, contratos, etc.). Aún hoy, la espada de Damocles del derecho comunitario oscila permanentemente suspendida sobre las cabezas de los gestores públicos. De ahí los esfuerzos realizados por nuestra doctrina para sistematizar y traducir en lo posible este corpus jurisprudencial al ámbito de nuestro derecho positivo ${ }^{14}$.

13 Cfr. V. A. Janssen (2014), «The Institucionalised and Non-Institutionalised Exemptions from EU Public Procurement Law: towards a more coherent approach?», Utrecht Law Review, 10, 5 (diciembre), pág. 180.

14 Pueden verse en este sentido los trabajos de J. M. Gimeno Feliú (2006), La nueva contratación pública europea y su incidencia en la legislación española, Madrid: Thomson Civitas, en especial págs. 127-151; M. Fuertes López y F. Sosa Wagner (2007), «¡Pueden los contratos quedar en casa? La polémica europea sobre la contratación in house», Diario La Ley, 6.715, 17 de mayo; J. V. González García (2007), «Medios propios de la Administración, colaboración administrativa y sometimiento a la normativa comunitaria de contratación», Revista de Administración Pública 173, págs. 217-237; M. A. Bernal Blay (2008), «Un paso en falso en la interpretación del criterio del control análogo al de los propios servicios en las relaciones in house. Comentario a la STJUE de 19 de abril de 2007», Revista Española de Derecho Administrativo, 137, págs. 115-138. B. Noguera de la Muela (2010), «Los encargos in house en la Ley de Contratos del Sector Público. Especial referencia a los mismos en el ámbito local a la luz de la reciente jurisprudencia comunitaria", Revista de Administración Pública, 182, págs. 159-190; J. J. Pernas García (2008), Las operaciones in house y el Derecho comunitario de contratos públicos: análisis de la jurisprudencia del TJCE, Madrid: Iustel; E. Montoya Martín (2011), «La delimitación de los encargos domésticos: presupuesto para evitar la huida de las grarantías de la contratación pública», en F. López Menudo (coord.), Derechos y garantías del ciudadano: estudios en homenaje al profesor Alfonso Pérez Moreno, Madrid: Iustel, págs. 859-907; más recientemente, cfr. I. Gallego Córcoles (2015), «Los encargos a medios propios y servicios técnicos en la jurisprudencia del TJUE», Contratación Administrativa Práctica, 140, noviembre-diciembre, págs. 70-78. 


\section{EL NUEVO PLANTEAMIENTO DE LAS DIRECTIVAS DE CONTRATACIÓN DE 2014}

Ya desde la Comunicación de la Comisión Europea de 11 de marzo de 1998, las instituciones comunitarias han sido conscientes de la necesidad de aclarar la regulación de estas cuestiones ${ }^{15}$. El propio Parlamento Europeo se pronunció al respecto solicitando una mayor esfuerzo a la Comisión y a los Estados miembros para la difusión de las implicaciones jurídicas de las sentencias del TJUE en la materia ${ }^{16}$.

Sin embargo, ese empeńo no se reflejó más que en documentos interpretativos carentes de eficacia normativa, y aun así, de fecha tardía. Consciente de esta situación, el Libro Verde de la Comisión de 27 de enero de 2011, elaborado con vistas a la formulación del nuevo paquete de directivas de 2014, expuso la "cooperación dentro del sector público» como una de las cuestiones esenciales a afrontar por la política de modernizacion de la contratacion europea $^{17}$. Se recoge ahí la distinción de dos grandes modalidades de cooperación,

15 Véase Comunicación de la Comisión «La contratación pública en la Unión Europea», de 11 de marzo de 1998, COM (98) 143, en la que se enuncian ya los principales enfoques del futuro paquete de directivas de 2004. Enfoques generales (simplificación, adaptación a la evolución del mercado, lucha contra la corrupción, desarrollo de un entorno favorable a las pymes, sinergia con otras políticas, contratación electrónica eficaz...) que son coincidentes con los incluidos en las directivas de 2014, conforme a ese mecanismo de desarrollo de las políticas públicas comunitarias que es la rolling agenda. En la página 11 la Comisión anunciaba que se proponía aclarar a través de un documento interpretativo «los contratos «in house» es decir los que se adjudican en el seno de la Administración pública, por ejemplo entre Administración central y local o entre una Administración y una sociedad que es íntegramente propiedad de ésta».

16 Véase el Informe elaborado, a iniciativa propia, por la diputada europea Heide Rühle, «Nuevos aspectos de la política de contratación pública» (Resolución del Parlamento Europeo, de 18 de mayo de 2010, sobre nuevos aspectos de la política de contratación pública, 2009/2175 [INI]).

17 Libro Verde de la Comisión sobre la modernización de la política de contratación pública de la UE de 27 de enero de 2011 (COM 201115 final) que se subtitula «Hacia un mercado europeo de la contratación pública más eficiente». En él, dentro de la «mejora de las herramientas de las que disponen los poderes adjudicadores», se dedica un apartado específico a la cooperación dentro del sector público, public-public cooperation en la versión inglesa, en el que se reflexiona cómo «debe trazarse una línea divisoria entre los acuerdos entre poderes adjudicadores para llevar a cabo sus tareas amparados por su derecho a la organización autónoma, por un lado, y las actividades de contratación que deben beneficiarse de una competencia abierta entre los operadores económicos, por otro». 
la «cooperación vertical/institucionalizada» y la cooperacion horizontal, así como la «transferencia de competencias de una entidad a otra para la realización de una tarea pública». Tres modalidades de gestión pública a las que no les resultan aplicables las directivas, y para cuya regulación más segura el Libro Verde sugirió dos cosas.

- La primera se plasma en el Documento de trabajo de los servicios de la Comisión relativo a la aplicación de la normativa sobre contratación pública de la UE a las relaciones entre poderes adjudicadores (cooperación dentro del sector público), de 4 de octubre de $2011^{18}$, en el cual la Comisión procedió a sistematizar los distintos case law sometidos al TJUE a lo largo de los últimos años, así como sus consecuencias prácticas para las técnicas de colaboración horizontal y vertical, pero respetando el papel interpretativo auténtico del derecho comunitario que le corresponde al TJUE.

- La segunda propuesta es la incorporación a las directivas de reglas específicas sobre la materia.

Esto es lo que ha pasado en las directivas de 26 de febrero de 2014, que han aportado ese nuevo régimen en el largo art. 12 de la Directiva 24 bajo el equívoco epígrafe "contratos públicos entre entidades del sector público»" ${ }^{19}$.

18 Véase documento SEC (2011) 1169 final, de 4 de octubre de 2011, elaborado por la Dirección General de Mercado Interior y Servicios. En él se afirma que: «Es necesario, por tanto, distinguir entre las actividades de contratación que deberían estar sujetas a la libre competencia entre los operadores económicos, tal y como establecen las normas sobre contratación de la UE, y otros acuerdos que los poderes adjudicadores puedan utilizar para el ejercicio de sus tareas públicas y que no entran en el ámbito de aplicación de las Directivas sobre contratación pública de la UE» (SEC(2011) 1169 final, de 4.10.2011, pág. 3).

19 En la versión original de la propuesta de directiva realizada por la Comisión el 20 de diciembre de 2011 (COM (2011) 896 final), el epígrafe del entonces art. 11 era «relaciones entre poderes públicos», lo cual reforzaba la idea de exclusión de estos negocios jurídicos. Idea necesaria no solo por razones de oportunidad, sino incluso por razones de coherencia lógica: téngase en cuenta que estos negocios no satisfacen en principio un requisito esencial con el que la propia directiva define la noción de «contrato público»: la onerosidad. Recuérdese el tenor del art. 2.1.5) de la Directiva 24, que define así los contratos públicos: «los contratos onerosos celebrados por escrito entre uno o varios operadores económicos y uno o varios poderes adjudicadores, cuyo objeto sea la ejecución de obras, el suministro de productos o la prestación de servicios». Sin embargo, tras su paso por el Parlamento Europeo, el encabezamiento del epígrafe se ha inclinado por la noción "contratos públicos» en una suerte de pancontractualismo muy presente, por lo demás, en las opiniones de ciertos abogados generales. Sobre 
En la Directiva 23 de concesiones de servicio, la materia es objeto del homólogo artículo 17 de la Directiva 23 («concesiones entre entidades del sector público»). Por su parte, la Directiva relativa a la contratación por entidades que operan en los sectores del agua, la energía, los transportes y los servicios postal, dedica una subsección a esta materia (relaciones especiales: cooperación, empresas asociadas y empresas conjuntas, artículos 28 a 30). La alta densidad normativa de estos preceptos, su contenido incondicionado, claro y preciso, propició la adquisición de efecto directo de la mayor parte de estas nuevas determinaciones en nuestro derecho interno a partir del 18 de abril de $2016^{20}$.

Las directivas aportan tres grandes enfoques o ejes de política jurídica en esta materia:

a) Se reconoce explícitamente el «principio de libertad de administración de las autoridades públicas» (art. 2 Directiva 2014/23/UE), para «(...) decidir la mejor forma de gestionar la ejecución de obras o la prestación de servicios,

el contenido e impacto de las directivas, véase J. M. Gimeno Feliú (2014), El nuevo paquete legislativo comunitario sobre contratación pública: de la burocracia a la estrategia, Cizur Menor: Thomson Reuters Aranzadi.

20 Cfr. I. Gallego Córcoles, «Nuevos desarrollos de la contratación in house...», op. cit., pág. 188, con cita del Informe $1 / 2016$ de 6 de abril, de la Junta Consultiva de Contratación Administrativa de Cataluña, y L. Moll Fernández-Figares (2017), Los encargos a medios propios en la legislación actual, Madrid: Editorial Reus, pág. 85. En su Dictamen A. G. Entes Públicos 3/2.015 (R 61 2015), la Abogacía del Estado consideró también que el art. 12 de la Directiva 24 era susceptible de producir efecto directo, por contener reglas incondicionadas, completas y sin necesidad de concreción ulterior por los Estados miembros: «En este punto debe indicarse, por tratarse de un extremo de gran relevancia, que, como se desprende de la lectura del artículo 12 de la repetida Directiva, esta norma de Derecho de la Unión Europea establece en la materia que disciplina una regulación muy detallada y pormenorizada que, por ello, hace realmente innecesaria la promulgación de una norma de Derecho nacional que desarrolle o complete las previsiones de aquélla a fin de posibilitar su efectiva aplicación». El Tribunal de Cuentas ha aplicado ya la determinación del porcentaje de actividad a determinados medios propios sometidos a fiscalización, incluso antes de que la Directiva adquiriese efecto directo con fecha 18 de abril de 2016. Véase, por ejemplo, el informe de fiscalización del INECO fechado el 4 de noviembre de 2015. En su reunión de 1 de marzo de 2016, los tribunales administrativos de contratación pública acordaron considerar directamente aplicable la mayor parte del art. 12 de la Directiva 24, pero se ha mostrado más cauto respecto del art. 17 de la Directiva 23 (véase el documento «Los efectos jurídicos de las directivas de contratación pública ante el vencimiento del plazo de trasposición sin nueva ley de contratos del sector público», págs. 21-23 y 54-55). 
en particular garantizando un alto nivel de calidad, seguridad y accesibilidad económica, la igualdad de trato y la promoción del acceso universal y de los derechos de los usuarios en los servicios públicos. Dichas autoridades podrán optar por realizar sus funciones de interés público con recursos propios o en colaboración con otras autoridades o confiarlas a operadores económicos» ${ }^{21}$. Del mismo modo, el considerando 5 de la Directiva 2014/24/UE subraya que «debe recordarse que ninguna disposición de la presente Directiva obliga a los Estados miembros a subcontratar o a externalizar la prestación de servicios que deseen prestar ellos mismos o a organizarlos de otra manera que no sea mediante contratos públicos en el sentido de la presente Directiva. Ha de quedar excluida la prestación de servicios basada en disposiciones legales o administrativas, o contratos de trabajo».

Esto, a nuestro juicio, equivale a reconocer la autoprovisión administrati$v a$, en sus versiones horizontal y vertical, como una opción lícita y compatible con el derecho derivado comunitario. Se trata del explícito reconocimiento de la soberanía de los Estados miembros para optar por distintos modelos de economía (mixta) de mercado; dicho de otra forma, libertad para decidir si presta los servicios de su competencia bien a través de sus propios medios o en colaboración interadministrativa (es decir, dentro del perímetro del sector público), o bien a través de empresas privadas, mediante externalización contractual (private outsourcing). Estamos ante el reconocimiento de una potestad discrecional para adoptar las denominadas make-or-buy decisions ${ }^{22}$ en función de lícitos criterios de oportunidad. Y en esas decisiones, el concepto que engloba a las dos formas de prestación de servicios dentro del sector público (mediante recursos propios o en colaboración interadministrativa) es la autoprovisión

21 En la Directiva de sectores excluídos, la 2014/25/UE, el art. 1.4 establece que «La presente Directiva no afecta a la libertad de los Estados miembros de definir, de conformidad con la legislación de la Unión, lo que consideran servicios de interés económico general, cómo deben organizarse y financiarse dichos servicios con arreglo a las normas sobre las ayudas públicas y a qué obligaciones específicas deben supeditarse. La presente Directiva no afecta al derecho de los poderes públicos a todos los niveles de decidir si desean prestar servicios públicos por sí mismos, en qué forma y en qué medida, de conformidad con el artículo 14 del TFUE y con el Protocolo no 26».

22 Cfr. A. Sánchez Graells (2011), Public procurement and the EU competition rules, Oxford-Portland: Hast Publishing, pág. 232. Entre nosotros, esto ha sido defendido previamente por la mayoría de autores. Cfr. A. Huergo Lora (2001), «La libertad de empresa y la colaboración preferente de las Administraciones con las empresas públicas», Revista de Administración Pública, 154, pág. 161; Manuel Rebollo Puig (2003), «Los entes institucionales de la Junta de Andalucía y su utilización como medio propio", Revista de Administración Pública, 161, págs. 379-380. 
administrativa, que sería la técnica alternativa a la compra pública a través del mercado.

De ahí que, en general, las distintas formas de autoprovisión (ejecución por los servicios de la propia Administración, prestación de servicios en régimen de colaboración o mandatos de ejecución obligatoria de obras, suministros o servicios entre poderes adjudicadores del sector público) estén en general excluidas de las directivas, siempre que se den los requisitos necesarios en cada caso ${ }^{23}$.

b) En segundo lugar, la voluntad comunitaria de codificar, tamizándo$\mathrm{la}^{24}$, la variada y casuística jurisprudencia del TJUE sobre la cooperación vertical y horizontal no institucionalizada.

Las instituciones comunitarias han concretado reglas positivas generales sobre la operativa in house, incorporando lo esencial de la jurisprudencia del TJUE a dos grandes modalidades: la cooperación vertical mediante encargos a entidades personificadas (la jurisprudencia Teckal), y la cooperación horizontal entre entidades del sector público (en este último caso, a partir de la jurisprudencia Hamburgo, asunto C-480/06, Comisión/Alemania) ${ }^{25}$. Reglas que codifican el margen interpretativo de apreciación a las autoridades nacionales, y tratan de aportar la necesaria seguridad jurídica en la aplicación del derecho comunitario, fundamentalmente con las miras puestas en lograr la máxima eficiencia, al tiempo que se evitan distorsiones al limpio funcionamiento competitivo del mercado interior ${ }^{26}$.

23 Recuérdese lo que dice el considerando 31 de la Directiva 2014/24: «El hecho de que las dos partes de un acuerdo sean poderes públicos no excluye por sí mismo la aplicación de las normas de contratación. No obstante, la aplicación de las normas de contratación pública no debe interferir con la libertad de los poderes públicos para ejercer las funciones de servicio público que le han sido conferidas utilizando sus propios recursos, lo cual incluye la posibilidad de cooperación con otros poderes públicos. Es preciso asegurar que la cooperación entre entidades públicas exentas no acabe falseando la competencia con respecto a los operadores económicos privados, hasta el punto de situar a un proveedor de servicios privado en una posición de ventaja respecto de sus competidores».

24 Entre nosotros, I. Gallego Córcoles se ha ocupado de inventariar los matices con los que el art. 12 ha introducido la jurisprudencia comunitaria. Cfr. «Los encargos a medios propios y a servicios técnicos en la jurisprudencia del TJUE», op. cit. págs. 70-78.

25 Véase M. A. Bernal Blay (2011), «La cooperación administrativa horizontal como fórmula de organización. Su articulación en el ámbito local desde la óptica del Derecho de los contratos públicos», en J. M. Gimeno Feliú (coord.), Organización Local, Nuevas tendencias, Cizur Menor: Thomson Civitas, págs. 361-376.

26 Cfr. S. Arrowsmith (2014), The Law of Public and Utilities Procurement: Regulation in the EU and the UK, vol. 1, 3a edición, London: Sweet and Maxwell, pág. 501. 
Ahora bien, las directivas han introducido algunas acotaciones nuevas, no contempladas en la jurisprudencia. Pero por ser de naturaleza directiva, el conjunto resultante está sometido al desarrollo por los Estados miembros. Estos tienen la obligación de integrar estas reglas en su derecho interno mediante sus propias estrategias de adaptación de sus normas y sectores públicos ${ }^{27}$.

c) En tercer lugar, la flexibilización de los criterios de utilización de los medios propios, en especial, en relaciones de cooperación horizontal, arts. 12.4, 17.4 y 28.4 de las directivas, que incorporan la jurisprudencia Hamburgo: las directivas han acabado por reconocer la realidad de geometría variable que sobre tales criterios ha ido acuñándose sentencia a sentencia del TJUE a lo largo de los años ${ }^{28}$, aportando una mayor flexibilización, como el hecho de no excluirse la participación privada en los poderes adjudicadores que traben entre sí relaciones verticales u horizontales.

En efecto, para las relaciones verticales esta posibilidad se contempla por el art. 12.1.b) de la Directiva 24. Para las relaciones horizontales, el texto final de las directivas refleja en este punto la posición del Consejo Europeo, no de la Comisión (cuya propuesta original incluía el límite de la participación privada ${ }^{29}$ ) ni

27 Como ha destacado V. Janssen, "Contrary to the common beliefs of many Member States, there is a national discretionary power to provide further clarification of many aspects of this harmonization measure. Article 12 Directive on public procurement appears to be minimum harmonization and, thus, still leaves open many opportunities for the Member States to adopt their own legislation or policy in relation to these important - and widely used - exemptions from public procurement law», cfr. «The Institucionalised and Non-Institutionalised exemptions from EU Public Procurement Law: towards a more coherent approach?», op. cit., pág. 180. Entre nosotros, D. Santiago Iglesias propuso una fórmula de trasposición no seguida por el legislador en «Las relaciones de colaboración entre poderes adjudicadores excluidas de la normativa de contratación del sector público: una propuesta de transposición de la regulación contenida en las Directivas de contratación al ordenamiento espańol» (2015), Revista General de Derecho Administrativo, 38.

Cfr. J. J. Pernas García (2009), «La expansión de la excepción in house y la flexibilización progresiva del criterio del 'control análogo'. Comentario a la sentencia del TJCE de 13 de noviembre de 2008", Revista Contratación Administrativa Práctica, 87, junio; K. Wauters (2015), Cooperative agreements between publico authorities. The influence of CJEU case law on national legal systems, op. cit., pág. 165.

29 El punto 4 del art. 11 de la propuesta inicial de la Comisión, de 20 de diciembre de 2011, rezaba que: «Un acuerdo celebrado entre dos o más poderes adjudicadores no se considerará un contrato público a efectos de lo dispuesto en el artículo 2, punto 6, de la presente Directiva, cuando se cumplan todas y cada una de las condiciones siguientes: (a) que el acuerdo establezca una cooperación genuina entre los poderes adjudicadores participantes para el desempeńo conjunto de sus tareas 
del Parlamento ${ }^{30}$, lo cual significa que los Estados miembros han apostado por superar el enfoque restrictivo del TJUE sobre la cooperación horizontal entre autoridades públicas, que toca un núcleo sensible de la soberanía estatal ${ }^{31}$. Esta flexibilización y normalización deben señalarse especialmente en cuanto tienen de superación de criterios restrictivos señalados anteriormente por esta jurisprudencia ${ }^{32}$, pues ahora se admite con naturalidad lo que el considerando 33 ha enunciado como «contratos para la prestación conjunta de servicios

de servicio público e implique derechos y obligaciones mutuos de las partes; (b) que el acuerdo se rija únicamente por consideraciones de interés público; (c) que los poderes adjudicadores participantes no realicen en el mercado libre más del 10 $\%$, en términos de volumen de negocios, de las actividades pertinentes en el contexto del acuerdo; (d) que el acuerdo no implique transferencias financieras entre los poderes adjudicadores participantes, excepto los correspondientes al reembolso de los costes reales de las obras, los servicios o los suministros; (e) que no exista participación privada en ninguno de los poderes adjudicadores participantes». Además, el párr. 5 del art. 11 añadía lo siguiente: «La inexistencia de participación privada contemplada en los apartados 1 a 4 se comprobará en el momento de la adjudicación del contrato o de la celebración del acuerdo. Las exclusiones previstas en los apartados 1 a 4 dejarán de aplicarse a partir del momento en que se efectúe cualquier participación privada, con la consecuencia de que deberá convocarse una licitación para la adjudicación de los contratos vigentes a través de los procedimientos de contratación normales».

Cuya enmienda en este punto (83) clonaba la regla de la cooperación vertical, según la cual «les pouvoirs adjudicateurs participants ne font l'objet d'aucune participation privée, à l'exception des formes de participation privée sans contrôle ou imposées par la loi, conformément aux traités, qui n’influent pas sur les décisions du pouvoir adjudicateur qui exerce le contrôle».

31 Cfr. K. Wauters, Cooperative agreements between publico authorities... op. cit., pág. 166; S. Arrowsmith, The Law of Public and Utilities Procurement, op. cit., pág. 528. Francisco Javier Villar Rojas (2017) ha apuntado acertadamente que la exposición de motivos de la Directiva 2014/23/UE de concesiones acepta expresamente esta participación en su considerando 46: «También debe aclararse que los poderes o entidades adjudicadores tales como los organismos de Derecho Público que pueden tener una participación de capital privado deben estar en condiciones de hacer uso de la excepción por cooperación horizontal». Cfr. «Los contratos para la prestación conjunta de servicios públicos locales», REALA, 7, pág. 13.

32 S. Arrowsmith, por su parte, ha seńalado que el hecho de que el art. 12 de la Directiva 24 considere excluidas de las directivas las situaciones de autoprovisión —más que exentas de su aplicación — supone una aceptación formal de una interpretación «normal» de tales situaciones, superando así su interpretación restrictiva tradicional por el TJUE. Cfr. The Law of Public and Utilities Procurement, op. cit., págs. 517 y 527. 
públicos», siempre que se guíen por la idea de una cooperación no falseadora del mercado ${ }^{33}$.

Con toda probabilidad, ello conducirá a un cambio de eje de la autoprovisión desde lo vertical (la lógica del medio propio y del encargo obligatorio) a lo horizontal (la lógica de colaboración público-público mediante fórmulas conveniales), por decirlo en la terminología común de la Comisión Europea. Tal cambio de eje será animado y acompañado por la exclusión explícita de las traslaciones competenciales interadministrativas que ahora prevén los arts. 1.6 de la Directiva 2014/24/UE y 1.4 de la Directiva 2014/23/UE: «Los acuerdos, las decisiones y los demás instrumentos jurídicos mediante los cuales se organiza la transferencia de competencias y responsabilidades para desempeñar funciones públicas entre poderes adjudicadores o agrupaciones de los mismos y que no prevén que se dé una retribución por la ejecución de un contrato, se consideran un asunto de organización interna del Estado miembro de que se trate y, en ese sentido, en modo alguno se ven afectados por la presente Directiva». Exclusión que ya ha dado pie, por cierto, a un pronunciamiento interpretativo del TJUE mediante Sentencia de 21 de diciembre de 2016, en el asunto Remondis ${ }^{34}$.

\section{AUTOPROVISIÓN, MERCADO Y COMPETENCIA}

La plasmación de estos tres ejes en las directivas ha dado paso a un escenario de reconfiguración y mutación de las relaciones entre autoprovisión y mercado, entre autonomía administrativa e integración de mercado, cuya tensión no va a ser menor que en años anteriores: será simplemente distinta y más rica. Cada país deberá realizar su lectura y aprovechamiento de las oportunidades que se ofrecen. Para ello, conviene tener presente que, aunque pueda acabar siéndolo por malas prácticas, la autoprovisión no es intrínsecamente contraria a la competencia: puede serlo si se aprovecha para dotar de ventajas comparativas a personificaciones públicas instrumentales con vocación predominante de operar en el mercado.

33 F. J. Villar Rojas (2017) ha analizado el impacto de estos extremos de las directivas sobre el derecho español en su trabajo «Los contratos para la prestación conjunta de servicios públicos locales», op. cit., págs. 5-18.

34 Sobre el alcance y requisitos del art. 1.6 se ha pronunciado la Sentencia de 21 de diciembre de 2016, Remondis (asunto C-51/15), que giraba sobre si la constitucion de un consorcio intermunicipal con la imputación de las correspondientes competencias de prestación de servicios públicos podía considerarse un contrato público. Materia en la que es también relevante la Sentencia de 18 de diciembre de 2007, Comisión contra Irlanda (asunto C-532/03). 
Pero fuera de estas patologías, nada impide que se optimice el aprovechamiento de las posibilidades ofrecidas por el propio sector público para la satisfacción de necesidades vinculadas a los servicios públicos. Es más, en una economía social de mercado, el aprovechamiento de los recursos que pueda proporcionar el sector público para la atención del interés público es una herramienta necesaria e irrenunciable incluso en términos de eficiencia y racionalidad, de conformidad con el art. 31.2 de la Constitución, dado que si el sector público es capaz de proveer entre sí bienes y servicios de calidad a un precio más asequible que el sector privado, no puede haber más razones que las ideológicas para rechazar esta opción de gestión. De ahí que la estrategia jurídica más ajustada a este escenario sea la que reconduzca, regule y aproveche sus posibilidades.

Una regulación inteligente de la autoprovisión no excluye, de hecho, el estímulo de la competencia interna dentro del sector público (lo que podríamos denominar cuasimercados públicos de prestación de servicios en régimen de autoprovisión), ni la competencia entre el sector público y el privado ${ }^{35}$. Antes al contrario, las presupone cuando la autoprovisión se construye conforme a los principios jurídicos de eficiencia y eficacia que pautan el general funcionamiento de la Administración. De ahí la importancia de anticipar ese escenario en el marco de nuestro derecho público, aquejado desde hace años de una peculiar dinámica de desajuste que describimos a continuación.

35 Bajo el mandato de George W. Bush, la Administración federal norteamericana desarrolló a partir de 2001 el programa denominado US Competitive Sourcing Initiatives, mediante el cual se pretendía estimular la competencia del sector privado respecto de un sector público, el norteamericano, que satisface de manera eficiente aún hoy muchas de las necesidades de sus servicios públicos. La iniciativa pretendía exteriorizar anualmente las necesidades de tipo comercial de las agencias federales para abrirlas a competencia con el sector privado, sin perjuicio de su prestación final por el propio sector público federal a través de un fee-for-service agreement cuando esta fuese la opción más eficiente. Véase https://www.dol.gov/oasam/programs/boc/competitivesourcing/. También en Nueva Zelanda se han inspirado en estas ideas, y mantienen una amplia capacidad de prestación de servicios entre administraciones y agencias gubernamentales (dentro de los denominados opt-out procurements); véase Government rules of sourcing, $3^{a}$ ed., 2015, en especial pág. 16). 


\section{LOS DESAJUSTES ESTRUCTURALES DEL DERECHO PÚBLICO ESPAÑOL}

\section{LA AUTOPROVISIÓN, ENTRE LA LÓGICA DE LA SOSPECHA Y UN USO GENERALIZADO}

Por la peculiar aproximación del derecho comunitario a la autoprovisión administrativa como una excepción lícita de las normas de concurrencia en materia de compra pública, la lógica de la sospecha se ha convertido en la actitud predominante en Espańa a la hora de valorarla jurídicamente.

Sea desde posiciones que contemplan estas técnicas como ingeniosas fórmulas para posibilitar patologías corruptas de los gestores públicos (adjudicación de contratos a dedo, cesiones ilegales de trabajadores, etc.), sea desde posiciones que las consideran prácticas incompatibles con la garantía de la concurrencia del sector privado, tanto los encargos de ejecución obligatoria como los convenios y encomiendas de gestión han sido puestos frecuentemente en cuestión.

Por esta razón, el trabajo fiscalizador del Tribunal de Cuentas ha sido especialmente intenso en los últimos años en este ámbito ${ }^{36}$. Años de crisis, durante los cuales se ha experimentado una fuerte proliferación de la operativa con encomiendas de gestión y medios propios: la $\mathrm{CNC}$ ha señalado que el número de entidades con la consideración de medio propio se ha triplicado en seis años, desde 2007 a 2012, coincidiendo con la crisis económica. Incluso el Informe CORA se ha hecho eco del uso del convenio interadministrativo y de su importancia económica ${ }^{37}$. Testimonios empíricos del incremento de la utilización de las técnicas de la autoprovisión administrativa durante la coyuntura de la crisis, del cual la atribución formal de la consideración de medio propio, o las encomiendas publicadas en diarios oficiales, son fiables marcadores.

Este fenómeno no debería sorprendernos. Como ha ocurrido ya durante otras épocas más o menos recientes de «vacas flacas», los medios propios han sido utilizados con frecuencia como respuesta de los gestores públicos ante las

36 Véase el resumen de todo este trabajo fiscalizador en la moción del Tribunal de Cuentas a las Cortes Generales sobre la necesidad de desarrollar un adecuado marco legal para el empleo de las encomiendas de gestión por las administraciones públicas, de 22 de diciembre de 2016 (1.198), págs. 13-15. Véase también la moción del Tribunal de Cuentas a las Cortes Generales sobre la necesidad de establecer un adecuado marco legal para el empleo del convenio de colaboración por las administraciones públicas, de 30 de noviembre de 2010 (878).

37 Cfr. Informe CORA, pág. 191. 
rigideces administrativas (para la dotación de personal público por capítulo I por la existencia de unas especialmente restrictivas tasas de reposición, o rigideces derivadas de los procedimientos abiertos de contratación administrativa, modificación de contratos, etc.) o ante las propias debilidades de un sector privado endeudado y con malas prácticas («adicción al modificado», dilación en el cumplimiento de plazos de ejecución, tendencia resiliente a la captura de rentas públicas, etc.).

No es de extrañar, pues, que en una época que ha hecho de la eficiencia necesidad y virtud, la apuesta por la autoprovisión administrativa mediante el recurso a medios propios instrumentales se haya incrementado en el Reino de España, al margen de una regulación jurídica todavía tributaria de la visión de estas técnicas como una excepción. Revelador resulta que, en mayo de 2017, la institución promercado por excelencia, la Comisión Nacional de los Mercados y la Competencia, nada amiga de los encargos, haya encargado a TRAGSA la limpieza de sus sedes de Barcelona y Madrid por un total de 359187,78 euros.

\section{LA AUTOPROVISIÓN, ENTRE ORGANIZACIÓN, TÉCNICA DE GESTIÓN Y LIBRE CONCURRENCIA}

Uno de los factores que más ha pesado en la configuración desajustada del derecho público español ha sido la falta de perspectiva unitaria de las tres caras o facetas que configuran la autoprovisión administrativa: la faceta organizativa, la faceta operativa y la faceta concurrencial en régimen de mercado.

En este punto, la fuerza gravitatoria de las directivas comunitarias ha atraído la regulación de estas tres facetas hacia la dimensión contractual, subrayando los aspectos operativos y concurrenciales en detrimento de los aspectos organizativos, que apenas recientemente el legislador básico ha abordado, bien que de manera fragmentaria e insatisfactoria, mediante la Ley 40/2015, de régimen jurídico del sector público.

\subsection{La faceta operativa}

Se trata de la perspectiva que, por la influencia comunitaria, ha sido predominante durante los últimos quince años en Espańa. Aquí, el foco se centra en la correcta articulación jurídica de las relaciones entabladas entre los medios propios y sus administraciones dominantes o matrices mediante concretos negocios no onerosos. La jurisprudencia in house providing del TJUE, como hemos visto, ha supuesto una profundización en la naturaleza jurídica no contractual de estos negocios. Estamos ante relaciones jerárquicas, encargos obligatorios destinados al cumplimiento de las misiones de servicio público. 
Si durante muchos ańos los medios propios han sido tan discretamente invisibles para el gran público como presentes en la gestión administrativa cotidiana, su operativa propia ha sido también una especie de misterio trinitario, a medio camino entre el contrato, la orden interna y la colaboración interadministrativa. De hecho, tan grande era el misterio de la differentia specifica entre estas figuras que ni siquiera hemos tenido consenso para ponerle un nombre y unos apellidos dogmáticos claros a las operaciones in house providing.

La traducción de todo ello a nuestro derecho positivo se acometió por el legislador básico de contratos de 2007, quien consideró oportuno incorporar a la Ley 30/2007, de 30 de octubre, algunos de esos criterios comunitarios a la hora de definir las posibilidades y requisitos de estos negocios jurídicos. Ahí nació la paradójica regulación que ha estado en vigor diez años: por un lado, la exclusión de estos negocios respecto del ámbito objetivo de aplicación de la Ley de Contratos y su remisión a normas especiales (art. 4.1.n); por otro lado, la simultánea inclusión (en el art. 24.6) de algunos parámetros básicos de definición organizativa de los medios propios y de su gestión operativa ${ }^{38}$. Parámetros básicos que deberían haber constituido el objeto específico y detallado, precisamente, de esas normas especiales extracontractuales, y que produjeron una suerte de contraproducente absorción del campo normativo, que solo algunas comunidades autónomas se atrevieron a superar, con mayor o menor profundidad y acierto, pero en todo caso con una notable fragmentariedad de soluciones.

Además de lo anterior, y al mismo tiempo, nuestro derecho - primero en el art. 15 de la Ley 30/1992, y ahora en el art. 11 de la Ley 40/2015mantiene una regulación básica de la figura de las encomiendas de gestión, cuyos perfiles propios como forma de alteración de la competencia administrativa han hecho correr ríos de tinta.

Ahora, a esta dualidad se suma la más extensa regulación básica de los convenios inter e intraadministrativos de colaboración, también prevista en los arts. 47 y siguientes de la Ley $40 / 2015^{39}$, que está destinada a colmar, al menos parcialmente, la remisión a normas especiales que se deriva de la

38 Cfr. J. Tejedor Bielsa, «Sociedades locales, idoneidad de medios propios y régimen de contratación», op. cit., pág. 402.

39 Son convenios interadministrativos los «firmados entre dos o más Administraciones Públicas, o bien entre dos o más organismos públicos o entidades de derecho público vinculados o dependientes de distintas Administraciones públicas, y que podrán incluir la utilización de medios, servicios y recursos de otra Administración Pública, organismo público o entidad de derecho público vinculado o dependiente, para el ejercicio de competencias propias o delegadas». Son convenios intraadministrativos los «firmados entre organismos públicos y entidades de derecho público vinculados o dependientes de una misma Administración Pública». 
exclusión de estos negocios por el artículo 4.1.c) del TRCLSP. Ni que decir tiene, sin embargo, que la distinción de estos convenios respecto de las encomiendas obligatorias hará correr nuevos ríos de tinta.

\subsection{La faceta concurrencial}

Estamos ante la relación de respeto/vulneración que la operativa administrativa in house puede suponer para la defensa de la competencia en el mercado interior, tal y como se diseña en nuestro ordenamiento por la Ley 15/2007, de 3 de julio.

Es decir, si los encargos o encomiendas dentro del sector público pueden entrañar prácticas colusorias prohibidas en el sentido del art. 1 de esta ley (todo acuerdo, decisión o recomendación colectiva, o práctica concertada o conscientemente paralela, que tenga por objeto, produzca o pueda producir el efecto de impedir, restringir o falsear la competencia en todo o parte del mercado nacional), teniendo en cuenta que, conforme al art. 4 de esta misma ley: «Sin perjuicio de la eventual aplicación de las disposiciones comunitarias en materia de defensa de la competencia, las prohibiciones del presente capítulo no se aplicarán a las conductas que resulten de la aplicación de una ley». A esta clave de depuración jurídica han respondido no pocas sentencias de los tribunales españoles que han afrontado, casi siempre en un sentido negativo, si la encomienda directa de trabajos públicos a ciertos medios propios y servicios técnicos de las administraciones — fundamentalmente, TRAGSA — suponen o no una vulneración de la libre competencia, por excluir de manera ilícita la concurrencia del sector privado en su satisfacción, o suponer una ventaja comparativa a un operador económico de naturaleza pública.

El contenido y problemas actuales de este enfoque puede verse ejemplificado en el informe elaborado en 2013 por la Comisión Nacional de la Competencia bajo el título «Los medios propios y las encomiendas de gestión: implicaciones de su uso desde la óptica de la promoción de la competencia», en el cual se lee (pág. 6) que «el recurso a las encomiendas, en particular cuando es sistemático, puede suponer condiciones menos ventajosas para las Administraciones demandantes que las que se derivarían de una licitación pública, una limitación de la posibilidad de acceso o expansión a determinados mercados por parte de operadores privados alternativos y una ruptura de la neutralidad competitiva en los bienes y servicios que estas entidades ofertan a otros demandantes, cuando ello sucede» ${ }^{40}$. Es decir, la $\mathrm{CNC}$ no prohíbe con carácter

40 Las principales restricciones a la competencia que se referenciaron en el Informe de la extinta CNC de 2013 fueron: la limitación del acceso a terceros, el cierre dinámico del 
general el uso de medios propios, pero sí señala la importancia de extremar el rigor en su utilización. De ahí su recomendación de aumentar los controles de eficiencia en el uso de estas técnicas, para que así su uso no suponga una ilícita - e ineficiente- huida de la concurrencia a la hora de proveer los bienes y servicios necesarios para el cumplimiento de las misiones de servicio público. Este empeño fue recogido posteriormente por la Ley 40/2015, como veremos a continuación, y por la Ley 9/2017.

\subsection{La perspectiva organizativa}

La perspectiva organizativa es el ámbito en el que nace uno de los dos criterios esenciales de la jurisprudencia in house providing: el control análogo.

Con independencia de la forma jurídica operativa que adopten las relaciones intra o interadministrativas, detrás de ellas hay siempre una Administración pública, entre cuyas potestades de autoorganización se sitúa la de constituir formas de personificación administrativa en régimen de descentralización funcional, a las que se atribuyen concretas misiones de servicio público. En este enfoque, lo predominante no es tanto la obligatoriedad del «encargo», sino la estructura "jerárquica» por la que circula: una estructura administrativa

mercado, la posible relajación de la concurrencia «aguas abajo»: la subcontratación y la opacidad: ausencia de publicidad, transparencia y centralización de la información. Posibles pérdidas de eficiencia en el aprovisionamiento respecto de la licitación (Informe de Medios Propios, pág. 39), en la medida en que la determinación competitiva del operador mediante licitación se sustituye por la atribución administrativa discrecional a un operador, eliminando las tensiones competitivas. Igualmente, aporta una menor capacidad de reducir las asimetrías de información, en perjuicio de la administración que se aprovisiona (pág. 43). Finalmente, consecuencias sobre la estructura de la oferta y la neutralidad competitiva en los mercados (pág. 51): la limitación de la posibilidad de acceso al mercado de operadores alternativos (pág. 51) y la ruptura de la neutralidad competitiva en mercados en que actúan los medios propios (pág. 54). Entre otras medidas, la CNC recomendaba: i) Incrementar la exigencia normativa de que el órgano de contratación justifique cada encomienda frente a la celebración de un contrato, considerando su impacto sobre la competencia efectiva en el mercado. ii) Limitar en la normativa la celebración de encomiendas de objeto excesivamente genérico. iii) Limitar en la normativa la posibilidad de que el poder adjudicador amplíe el contenido original de la encomienda a casos excepcionales, sujeto a probadas razones de interés público y sometido a condicionantes similares a los establecidos para la modificación del contrato público en el art. 105 TRLCSP. iv) Reducir normativamente la posibilidad de renovación automática en encomiendas que se sujeten a un plazo determinado. 
pública, con desdoblamientos instrumentales, pero integrantes todos ellos de un sector, el público, dotado de una alta capacidad de autopoiesis.

Esta perspectiva organizativa, sin embargo, ha sido escasamente desarrollada por el legislador básico de contratos de 2007, que se limitó a dos cosas: a) trasponer casi literalmente el contenido del control análogo en el art. 24.6 TRLCSP, añadiendo la exigencia de reconocimiento expreso de la condición de medio propio y servicio técnico por la norma que cree la entidad, o sus estatutos, y b) abrir la puerta a la constitución de sociedades públicas interlocales ${ }^{41}$.

Posteriormente, determinados derechos autonómicos (Navarra, Aragón, Galicia, Andalucía, etc.) han utilizado sus títulos sobre organización administrativa para incorporar sus propias «normas especiales» sobre medios propios y servicios técnicos, robusteciendo la trazabilidad de su funcionamiento. Más recientemente, en la estela de una preocupación generalizada en el seno de las juntas consultivas de contratación administrativa ${ }^{42}$, el legislador de la crisis

41 Frente a la anterior redacción del art. 85.2.d) LBRL, que hablaba de la «sociedad mercantil local, cuyo capital social pertenezca íntegramente a la entidad local o a un ente público de la misma» como fórmula de gestión directa, la redacción dada por la disposición final primera de la Ley 30/2007 al art. 85.2 d) LBRL hablaba de la «Sociedad mercantil local, cuyo capital social sea de titularidad pública». La actual LBRL mantiene esta redacción. Sobre ello, véase B. Noguera de la Muela (2010), «Los encargos in house en la Ley de Contratos del Sector Público. Especial referencia a los mismos en el ámbito local a la luz de la reciente jurisprudencia comunitaria", Revista de Administración Pública, 182; A. Koninckx Frasquet (2014), «Modos de gestión de los servicios públicos. Redimensión del sector público local y otras medidas de racionalización. En especial, la gestión directa», en M. Domingos Zaballos (dir.), Reforma del régimen local, Cizur Menor: Thomson Reuters Aranzadi, págs. 514 y ss.; Encarnación Montoya Martín (2009), Los medios propios o servicios técnicos en la Ley de Contratos del Sector Público. Su incidencia en la gestión de los servicios públicos locales, Barcelona: Fundación Democracia y Gobierno Local, págs. 140 ss. Finalmente, J. Tejedor Bielsa (2014), «Sociedades locales, idoneidad de medios propios y régimen de contratación», en el libro colectivo Observatorio de los Contratos Públicos 2013, Cizur Menor: Thomson Reuters-Civitas, págs. 361-420.

42 Véanse los Informes 2/2012, de 7 de junio, y 13/2012, de 27 de septiembre, de la JCCA. Este último informe incluso aplicaba un precepto no básico del art. 24 TRLCSP (el 4) a la intelección del párr. 6, sí básico, para considerar como básico el límite del $50 \%$ a la subcontratación de encomiendas. Recordemos que el TRCLSP solo aplicaba expresamente el límite del 50\% a la subcontratación para el caso de TRAGSA y TRAGSATEC, cuyo régimen se contiene en la disposicion adicional $25^{\circ}$. La posterior circular 4/2015, de la IGAE, de 20 de mayo, sobre diversos aspectos relacionados con las encomiendas de gestión reguladas en el art. 4.1.n) y 24.6 del TRLCSP, hizo suya esta discutible intepretación restrictiva de la JCCA. 
—el básico, pero también los autonómicos ${ }^{43}$ — ha proyectado en este ámbito criterios de racionalización de la planta, funcionamiento y técnicas de control del gasto similares en todo el sector público ${ }^{44}$.

La situación descrita ha evolucionado - bien que parcialmente - con la Ley 40/2015, cuyo art. 86 introdujo una regulación general de los medios propios y servicios técnicos de la Administración General del Estado (por tanto, no aplicable, en principio, a los medios propios locales y autonómicos), cuyo enfoque desarrolla la peculiar lógica de la sospecha contra los medios propios: apenas desde esta lógica se entiende la concepción de su utilización como una excepción que debe motivarse, y el conjunto de controles dispuestos desde los títulos organizativos del sector público para garantizar su idoneidad y eficiencid ${ }^{45}$,

43 El art. 8 de la Ley navarra de 2006 fue modificado a través de la Ley 2/2013, de 25 de febrero, para introducir nuevas reglas y garantías sobre los encargos a entes instrumentales. Cataluña, pese a haber aprobado el Decreto Ley 3/2016, de 31 de mayo, de medidas urgentes en materia de contratación pública, no ha estimado oportuno introducir regulación específica alguna sobre la materia que nos ocupa, manteniendo desde 2011 una especie de "cruce» entre encomiendas y encargos, que se refleja en los arts. 10 y 116 de su Ley 26/2010, de 3 de agosto, de régimen jurídico y de procedimiento de las administraciones públicas de Cataluña.

44 La Ley de Presupuestos Generales del Estado para 2012 introdujo algunas acotaciones al control del gasto de los medios propios. La disposición adicional sexta de la Ley de Presupuestos Generales del Estado para 2013 reguló una «encomienda general por la que se reestructura la prestación de servicios de administración electrónica realizados por la Fábrica Nacional de Moneda y Timbre-Real Casa de la Moneda en el ámbito de la Administración General del Estado». La disposición final décima cuarta de esta misma ley modificó el art. 21 de la Ley General Presupuestaria de 2003 para limitar al $10 \%$ en el ámbito de la Hacienda Pública estatal los anticipos autorizables en caso de encomiendas de gestión. La Ley de Presupuestos Generales del Estado para 2014 modificó el art. 74.5 de la Ley General Presupuestaria, en el sentido de requerir autorización del Consejo de Ministros todas aquellas encomiendas de gestión de la Administración General del Estado cuyo importe sea superior a 12 millones de euros. Véase J. M. Gimeno Feliú (2017), «La incidencia de la nueva Ley de Régimen Jurídico del Sector Público en el régimen de contratación de ciertos poderes adjudicadores y de la Ley de Procedimiento Administrativo Común en la posibilidad de control», Contratación Administrativa Práctica, 147, enero-febrero, para quien «Esta regulación limita, acertadamente, la utilización de la técnica del medio propio, adecuándola a su finalidad auto-organizativa y evitando la creación de "medios propios formales" con la intención de huir de las reglas y principios del derecho administrativo». En el mismo número de Contratación Administrativa Práctica, con más pormenor, véase el trabajo de I. Gallego Córcoles, «Los encargos a medios propios y servicios técnicos en la LRJSP», op. cit., quien destaca la doble delimitación conceptual de los negocios 
en la línea de lo recomendado por el propio Tribunal de Cuentas en el año $2013^{46}$.

Para evitar una utilización fraudulenta de esta técnica administrativa, se introducen una serie de criterios de motivación y de control de eficiencia de los encargos, con una doble proyección. En primer lugar, se trata de criterios que deberán acreditarse en el expediente de declaración como medio propio de cualquier entidad integrante del sector público institucional estatal, y que tienen un claro parentesco con los criterios de eficiencia y oportunidad introducidos por la Ley 27/2013 para controlar la discrecionalidad en la elección de formas instrumentales de gestión directa por parte de las entidades locales (nueva redacción dada al art. 85.2 LBRL).

Pero, en segundo lugar, el precepto da a entender que se trata de criterios aplicables en los concretos expedientes de gasto a que dé lugar la operativa mediante encomienda a medio propio y servicio técnico. Lo cual equivale a introducir regulaciones sustantivas de la operativa con medios propios. En la misma línea se sitúa la consideración de la gestión contractual indirecta como preferente frente a la utilización de medios propios, que el legislador considera excepcional y por tanto necesitada de especial motivación ${ }^{47}$.

Desde el punto de vista organizativo, más que una categoría propia de organismo público ${ }^{48}$, el denominado por el artículo 86 «medio propio y servicio técnico» es una condición que puede recaer en cualquier entidad integrante del sector público institucional estatal, siempre que acredite tres grandes requisitos: a) los previstos por el TRLCSP (art. 24.6), b) la disposición de medios suficientes e idóneos para realizar prestaciones en el sector de actividad que

jurídicos resultantes: la opción semántica a favor del «encargo» frente a la «encomienda de gestión» (concepto utilizado, como sabemos, por el TRLCSP desde 2007); y la distinción objetiva entre encomiendas de gestión (materia del art. 11 de la LRJSP: las encomiendas no pueden tener por objeto prestaciones propias de los contratos públicos) y encargos a medios propios. También ha destacado esta autora el carácter fragmentario de la regulación del art. 86 LRJSP.

46 Véase las recomendaciones del Informe 1.003, de 28 de noviembre de 2013, de fiscalizacion de la utilización de la encomienda de gestión regulada en la legislación de contratación pública por los ministerios, agencias y organismos autónomos del área político-administrativa del Estado, ejercicios 2008-2012, págs. 65-66.

47 Cfr. J. Bermúdez Sánchez (2015), «La modificación de los modos de gestión de servicios públicos en el Proyecto de Ley de régimen jurídico del sector público», Documentación Administrativa, 2, enero-diciembre, disponible en línea.

48 En este punto, la Ley 40/2015 sigue el tradicional planteamiento de la LOFAGE de 1997, que tampoco reconocía la categoría de los medios propios e instrumentales dentro de la taxonomía legal de los organismos públicos. 
se corresponda con su objeto social, y c) alguna de las dos circunstancias siguientes: 1) ser una opción más eficiente que la contratación pública y resulta sostenible y eficaz, aplicando criterios de rentabilidad económica; 2) resulte necesario por razones de seguridad pública o de urgencia en la necesidad de disponer de los bienes o servicios suministrados por el medio propio o servicio técnico. En cualquier caso, el precepto no aclara suficientemente si estamos ante parámetros de una declaración constitutiva del medio propio (que se aplicarían apenas en su acto de creación), o si se trata de parámetros de eficiencia que deban aplicarse en el giro o tráfico del medio propio sobre cada encomienda singular mediante la función de fiscalización interventora ${ }^{49}$.

Frente al tradicional reconocimiento de la condición de medio propio e instrumental, que se daba a posteriori cuando concurrían una serie de requisitos que no tenían que ver estrictamente con la naturaleza formal de organismo autónomo, entidad pública empresarial, consorcio, etc., sino con la función instrumental desarrollada, la Ley 40/2015 reduplica la senda de formalización introducida por el legislador de 2007 en el art. 24.6 TRCLSP, pero con una solución distinta, superpuesta a la normativa contractual básica del TRLCSP: frente al expreso reconocimiento de la condición de medio propio en norma o estatutos de creación del $24.6^{50}$, el art. 86 refuerza ahora los parámetros de eficiencia en su creación, pero al mismo tiempo permite la atribución de la condición mediante una "declaración», un acto administrativo cuya formalización jurídica singularizada está por verse en la práctica ${ }^{51}$, pero que en

49 Véase los criterios previamente previstos en el Acuerdo del Consejo de Ministros de 6 de junio de 2008, por el que se dan las instrucciones para la atribución de la condición de medio propio y servicio técnico a las sociedades mercantiles estatales cuyo capital corresponde en su integridad a la Administración General del Estado o a la Sociedad Estatal de Participaciones Industriales y a fundaciones constituidas con aportación íntegra de esta entidad (no publicado), así como el Acuerdo del Consejo de Ministros de 30 de mayo de 2008, por el que se da aplicación a la previsión de los arts. 152 y 147 de la Ley 47/2003 (contenidos básicos de la fiscalización previa), en particular, el punto decimoquinto, sobre expedientes de ejecución de trabajos por la propia administración (BOE, 143, de 13 de junio de 2008).

50 Sobre ello, véase, por ejemplo, el Informe de la Junta Consultiva de Contratación Administrativa de Aragón 26/2008, de 3 de noviembre, sobre la interpretación de la disposición adicional 13a de la Ley de Administracion de Aragón de 2001.

51 La disposición adicional sexta concedió un plazo de seis meses a contar desde su entrada en vigor ( 1 de octubre de 2016; o sea, 1 de abril de 2017) para que todas las entidades y organismos públicos que en ese momento tengan la condición de medio propio en el ámbito estatal se adapten a sus previsiones. En el $B O E$ no he encontrado ejemplos de declaraciones de medios propios y servicios técnicos en el sentido reque- 
cualquier caso parece estar dirigido a ampliar el ámbito operativo de las encomiendas obligatorias a entidades personificadas. En esta misma línea, el art. 86 permite expresamente la posibilidad de que entidades del sector público institucional que no sean poderes adjudicadores puedan realizar encargos obligatorios a medios propios, aspecto que será desarrollado posteriormente en la Ley $9 / 2017$.

La "guinda» de esta densa mezcla de aspectos organizativos y operativos es la obligación de ponerle "collar» al medio propio, para que los operadores jurídicos sepan que lo es: «En la denominación de las entidades integrantes del sector público institucional que tengan la condición de medio propio deberá figurar necesariamente la indicación "Medio Propio" o su abreviatura "M.P." ». Opción esta que parece inspirarse en una concepción formalista o tipológica - el medio propio como categoría instrumental típica- que no acaba de encajar bien, a mi juicio, con el diseño funcional que acomete este art. 86, es decir, con el hecho de que los medios propios sean una "condición» organizativa de la operativa singular con encargos obligatorios, que puede recaer tanto en un organismo autónomo, como una EPE, un consorcio, una fundación pública, una sociedad pública, etc., siempre que se den las condiciones ahora previstas por la Ley $9 / 2017$. Este solapamiento entre lo organizativo y lo contractual constituye, de hecho, uno de los puntos calientes de fricción que debía afrontar la nueva ley de contratos del sector público ${ }^{52}$.

Pero antes de ver sus resultados, importa concluir que el esfuerzo de la Ley 40/2015 fracasó en su intento de dotar de un régimen integral a la encomienda de gestión a medios propios. Es más, a nuestro juicio agravó más sus

rido por la Ley 40/2015. I. Gallego Córcoles (2016) considera que la declaración por acto administrativo de la condición de medio propio, aunque admitida en el derecho navarro, puede vulnerar la normativa comunitaria. Cfr. «Nuevos desarrollos de la contratación "In house» en el derecho español: los encargos a medios propios y servicios técnicos», en J. M. Gimeno Feliú (dir.), Observatorio de los Contratos Públicos 2015, Cizur Menor: Thomson Reuters Aranzadi, pág. 212.

52 En opinión de M. Álvarez Fernández (2016): «Esta previsión no tiene fácil acomodo en una Ley como la que se analiza y debería haberse incorporado a la normativa de contratos, pues, por una parte, la condición de medio propio o servicio técnico de una determinada entidad no le otorga una naturaleza jurídica distinta ni da lugar a una nueva categoría institucional, sino que es una simple cualidad que corresponde a la entidad de que se trate y, por otra parte, la ubicación sistemática del precepto hace que su regulación solo sea aplicable a los medios propios o servicios técnicos de la Administración General del Estado». Cfr. "Organización y funcionamiento de la Administración General del Estado y del sector público institucional en la Ley 40/2015», El Cronista del Estado Social y Democrático de Derecho, 63, pág. 66. 
contradicciones, al quedarse a medio camino justo en el momento en que ya el efecto directo de las directivas se cernía sobre nuestro derecho público.

\section{LOS NUEVOS DESAJUSTES DE LA LEY 9/2017, DE 8 DE NOVIEMBRE, DE CONTRATOS DEL SECTOR PÚBLICO}

Así las cosas, la nueva Ley 9/2017, de 8 de noviembre, de contratos del sector público, ha sido la norma encargada de trasponer a nuestro ordenamiento interno los artículos 17 y 12 de las directivas 23 y 24/2014.

En una primera lectura, parece evidente que se han traspuesto con apego literal los tres criterios de las directivas de 2014 conforme a los cuales la realización de encargos de cooperación vertical resulta compatible con el derecho comunitario de contratación pública. Sin embargo, un análisis más pormenorizado permite concluir que la política jurídica que inspira la trasposición española puede calificarse como poco coherente con la finalidad y sistemática de las directivas ${ }^{53}$. Frente a estas, en las que la autoprovisión administrativa se configura como una opción normal, no excepcional, a la hora de satisfacer la demanda interna de las administraciones de los Estados miembros, bien sea mediante técnicas de cooperación vertical u horizontal, el legislador español sigue partiendo de una visión restrictiva de estas técnicas, que se consideran excepcionales frente a la regla normal, que sería la externalización mediante contrato. Precisamente por ello, su enfoque se centra particularmente sobre la técnica de autoprovisión mediante cooperación vertical entre personificaciones instrumentales (que ahora pasan a denominarse «encargos»), cuya regulación se hipertrofia en la Ley 9/2017 para aumentar sus controles.

En este sentido, es cierto que se han aprovechado algunas de las recomendaciones realizadas por el Tribunal de Cuentas a lo largo de los informes de fiscalización acometidos sobre este sector en los últimos años ${ }^{54}$. Pero se ha

53 Criticando también las opciones de trasposición de las directivas en este punto, véase J. Alemany Garcías (2017), Los encargos a sociedades mercantiles de capital integramente público como medios propios en la legislación actual, Barcelona: Atelier, págs. 42-43. Véase también en un sentido crítico el trabajo de J. L. Martínez López-Muñiz (2017), «Sentido y alcance de la trasposición de las directivas de la Unión Europea (análisis particular en materia de contratación pública)», Revista de Administración Pública, 202, págs. 13-41.

54 Cuyo epítome es la Moción a las Cortes Generales sobre la necesidad de desarrollar un adecuado marco legal para el empleo de las encomiendas de gestión por las Administraciones Públicas, de 22 de diciembre de 2016, moción asumida por las Cortes Generales durante los trámites parlamentarios de elaboración de la Ley 9/2017 (sesión de la 
desatendido la que a nuestro juicio constituye la principal recomendación del Tribunal: «[...] una regulación integral de las encomiendas a medios propios, lo que abarca, además de los mencionados aspectos subjetivos, los aspectos objetivos, sustantivos, de procedimiento y de control que en la actualidad se encuentran desprovistos de una adecuada regulación, y que trascienden del ámbito regulativo de la legislación reguladora de la contratación pública» ${ }^{55}$. En un momento en que las directivas de contratos y el propio Tribunal de Cuentas aconsejaban segregar esta materia a una ley específica, se ha perdido una buena oportunidad de hacerlo. Ha pesado demasiado la inercia y el apego a los enfoques tradicionales de estas materias, dominantes en los grandes cuerpos de la Administración General del Estado, cuyo mantenimiento arroja resultados bien insatisfactorios.

La sistemática utilizada en este punto por la Ley 9/2017 para la trasposición de las directivas es, cuando menos, confusa. Más que ayudar a aclarar conceptos y regímenes jurídicos, hace lo contrario, continuando la senda de fragmentariedad e inseguridad jurídica en este ámbito. Frente al propio proyecto de ley de trasposición de la Directiva 25, que desarrollan en dos artículos (el 25, encargos a medios propios personificados, y el 26, convenios) los denominados «sistemas de cooperación pública excluidos» previstos por la directiva; y frente a otros derechos internos como el italiano ${ }^{56}$, el francés ${ }^{57} \mathrm{o}$ el portugués ${ }^{58}$, la Ley $9 / 2017$ da un tratamiento distinto a lo que la directiva

Comisión Mixta para las Relaciones con el Tribunal de Cuentas, de 27 de febrero de 2017) (BOE, 87, de 12 de abril).

55 Cfr. Moción a las Cortes Generales sobre la necesidad de desarrollar un adecuado marco legal para el empleo de las encomiendas de gestión por las Administraciones públicas, op. cit., pág. 12.

56 Véase el art. 5 del Codice dei Contratti Pubblici actualizado tras la ley de 21 de junio de 2016, incluido en el Título II, relativo a los contratos excluidos en todo o en parte del ámbito de aplicación. En él se recogen todas las formas, verticales y horizontales, de cooperación pública, incluidas las que se dan en base a derechos exclusivos en los sectores especiales.

57 Véase el art. 17 de la Ordonnance 2015-899 du 23 juillet 2015, relative aux marchès publics, que regula las «exclusiones aplicables a las relaciones internas del sector público» conocidas como quasi-régie (operaciones verticales in house) y el art. 18, que regula la cooperación horizontal entre poderes adjudicadores. Los arts. 19 y 20 se dedican respectivamente a las operaciones de provisión entre entidades adjudicadoras y empresas vinculadas.

58 Véanse los nuevos artículos 5 A y $5 \mathrm{~B}$ del Código português de Contratos Públicos, tras la reforma por Decreto Ley 111/2017, de 31 de agosto. Regulan respectivamente los «contratos en el ámbito del sector público» y su régimen, que queda sujeto «a los principios generales de la actividad administrativa, así como, con las debidas adapta- 
regula unitariamente. Las formas de cooperación vertical (ahora denominados «encargos» en nuestra "caja de herramientas») y las formas de cooperación horizontal («convenios de colaboración» $\mathrm{y}$ "encomiendas de gestión») son disgregadas en varios sentidos.

\section{ENCOMIENDAS DE GESTIÓN, CONVENIOS, ENCARGOS: DENTRO Y FUERA}

Dentro la sección de la ley destinada a regular los negocios jurídicos excluidos, desaparecen los encargos (anteriormente excluidos en el art. 4.1.n) TRLCSP), pero se mantiene (en concreto, en el art. 6) la regulación heredada de la exclusión de la aplicabilidad de la ley a los convenios de colaboración.

Expresamente, se añade ahora en el art. 6 la exclusión de las encomiendas de gestión reguladas por el art. 11 de la Ley 40/2015, cuya regulación, como norma especial extramuros de la ley de contratos, se mantiene incólume. Opino que estas opciones jurídicas son especialmente problemáticas, y dan lugar a un régimen verdaderamente cuántico, en el que estar y no estar al mismo tiempo es posible.

En efecto, el mantenimiento de la figura de la encomienda de gestión en la Ley 40/2015 como una técnica de alteración de elementos de la competencia administrativa situada extramuros de la LCSP y totalmente excluida de su aplicación es altamente distorsionador. No es esa, a mi juicio, su naturaleza propia $^{59}$. Más bien, esta figura no deja de ser una de las formas propias que

ciones a la naturaleza del contrato, a los principios de la contratación pública prevista en el $n^{\circ} 1$ del artículo $1 \mathrm{~A}$, debiendo siempre mencionarse la norma que fundamenta la inaplicación de la Parte II al contrato en causa. Los contratos susceptibles de calificación como acto administrativo y demás contratos sobre el ejercicio de potestades públicas quedan sujetos a las normas ordinarias del Código de Procedimiento Administrativo, con las necesarias adaptaciones». Sobre ello, véase D. Tiago Ferreira (2013), Contrataçao in House, Coimbra: Almedina, y del mismo autor, (2014) «O regime da contrataçao in house à luz das novas Directivas de contrataçao pública», Revista da Ordem dos Advogados, 74, págs. 769-794. Véase también A. Leitao (2011), Contratos interadministrativos, Coimbra: Almedina.

En este sentido, sobre la paulatina atracción de la encomienda de gestión al ámbito contractual, no cabe sino remitirse a los minuciosos trabajos de M. Vilalta-Reixach (2012), La encomienda de gestión. Entre la eficacia administrativa y la contratación pública, Cizur Menor: Thomson Reuters Aranzadi, en especial págs. 355 y ss.; y posteriormente (2016), «Los convenios interadministrativos en el ordenamiento jurídico español desde un punto de vista contractual», Revista Digital de Derecho Administrativo, 15, págs. 83-114. 
puede adoptar en nuestro derecho administrativo la cooperación horizontal prevista en los arts. 12.4 y 17.4 de las Directivas 24 y 23. Preceptos comunitarios que regulan conjuntamente todas las modalidades — verticales y horizontales- de autoprovisión y los requisitos cuya concurrencia las despoja de carácter contractual.

Siendo ello así, esta regulación interna fragmentada de técnicas de cooperación horizontal y vertical pierde la homología de la que gozan en la propia directiva, como fenómenos que son de un supraconcepto de autoprovisión administrativa (ejecución con recursos propios y relaciones de provisión mutua entre entidades del sector público que se caracterizan por la común ausencia de ánimo de lucro) que los excluye del ámbito de aplicación de las directivas, siempre que se ajusten a sus límites propios.

De hecho, la exclusión absoluta de las encomiendas de gestión por su comprensión como una forma no contractual de gestión de competencias supone, a mi juicio, una incorrecta trasposición de las directivas comunitarias, pues impide someterlas a las técnicas de control y depuración previstas para las figuras de cooperación entre entidades del sector público. Algo que en su día mereció sentencias de condena para el Reino de España ${ }^{60}$, fue materia del asunto Piepenbrock ${ }^{61}$, y probablemente no dejará de ser asunto polémico, a la vista de la confusión que sigue caracterizando la definición y uso de esta figura en nuestro derecho administrativo.

60 Sentencia de 18 de diciembre de 2007, asunto C-220/06. Se trataba de un convenio entre un Ministerio y Correos y Telégrafos por el que se establecía la prestación de diversos servicios postales, más allá del servicio postal universal. Recordando el concepto amplio de "decisión» susceptible de recurso contractual, véase la reciente Sentencia de 5 de abril de 2017, asunto C-391/15.

61 En su Sentencia de 13 de junio de 2013, asunto Piepenbrock (C-386/11), el Tribunal de Justicia critica precisamente la construcción del acuerdo de delegación del servicio de limpieza del Kreise de Düren a la ciudad de Düren, que incluía una tarifa de compensación de gastos, como una suerte de mandato, y no como una cooperación público-público: «[...] un contrato como el controvertido en el litigio principal, mediante el cual, sin establecer una cooperación entre las entidades públicas contratantes dirigida a la realización de una misión de servicio público común, una entidad pública encomienda a otra entidad pública la tarea de limpiar determinados edificios destinados a oficinas, locales administrativos y centros escolares, si bien la primera entidad se reserva la potestad de controlar que se lleva a cabo de manera correcta esta tarea, mediante una compensación económica que se considera debe corresponder a los costes incurridos por la ejecución de dicha tarea, estando además la segunda entidad autorizada a recurrir a terceros que pueden tener capacidad de operar en el mercado para la ejecución de la mencionada tarea, constituye un contrato público de servicios en el sentido del artículo 1, apartado 2, letra d), de la Directiva 2004/18». 
Mientras que en el caso de las encomiendas de gestión la exclusión o remisión es total ${ }^{62}$, no ocurre así respecto de los convenios de colaboración interadministrativa.

Su regulación, lejos de remitirse en bloque a la «aumentada» regulación básica de la Ley 40/2015 (arts. 47 a 53) como norma especial, y a otras normas sectoriales especiales (como la regulación de los convenios que articulan subvenciones directas en la Ley General de Subvenciones), se «enriquece» por la propia LCSP, precisamente mediante la incorporación de los criterios rectores de lo que la Directiva 2014/24/UE denomina cooperación horizontal, y que el legislador español desarrolla con más pormenor en el art. 31 de la Ley 9/2017. Precepto que camina en el sentido contrario a la concepción excepcional del recurso al convenio administrativo que sigue pautando la regulación española, en un alarde de incoherencia legislativa que no ha pasado desapercibido para la doctrina más atenta ${ }^{63}$.

Así, al requisito legal tradicional de exclusión de los convenios interadministrativos (que su objeto no coincida con el de algún contrato típico de la propia ley o en normas administrativas especiales, hoy doblemente incorporado

62 Art. 6.3: «Asimismo, quedan excluidas del ámbito de la presente Ley las encomiendas de gestión reguladas en la legislación vigente en materia de régimen jurídico del sector público». Probablemente, los redactores de la LCSP han considerado que, por ser la encomienda de gestión un negocio jurídico tradicionalmente encuadrado como técnica de alteración de competencias (así, en el art. 15 de la Ley 30/1992 y 11 de la Ley 40/2015), le sería de aplicación la exclusión prevista por el art. 1.6 de la Directiva 24: «Los acuerdos, las decisiones y los demás instrumentos jurídicos mediante los cuales se organiza la transferencia de competencias y responsabilidades para desempeñar funciones públicas entre poderes adjudicadores o agrupaciones de los mismos y que no prevén que se dé una retribución por la ejecución de un contrato, se consideran un asunto de organización interna del Estado miembro de que se trate y, en ese sentido, en modo alguno se ven afectados por la presente Directiva».

Véase en este sentido el análisis de A. Huergo Lora (2017), «Los convenios administrativos y la legislación de contratos públicos», REALA, 8, págs. 5-26, quien afirma con razón que «en nuestra legislación hemos llegado al absurdo de aplicar cumulativamente dos exigencias que son incompatibles entre sí», ańadiendo que «la Ley 40/2015 es una Ley "atrasada" en el sentido de que, a pesar de haberse aprobado en 2015, ignora la jurisprudencia surgida en 2009 y la Directiva de 2014, y permanece anclada en la interpretación literal de la sentencia de 13 de enero de 2005. La LCSP de 2017, aunque es conocedora de estos datos del marco jurídico comunitario, mantiene extemporáneamente el citado requisito de que el objeto del convenio no se corresponda con el de un contrato, que no es compatible con lo que dice la Directiva porque ésta ha venido precisamente a sustituirlo» (cfr. op. cit., págs. 7 y 15). 
al art. 47.1.3º de la Ley 40/2015 y al art. 6 Ley 9/2017) ${ }^{64}$, el legislador se ha limitado a añadir otros tres nuevos, acuñados por la jurisprudencia comunitaria $^{65}$ y positivados en los arts. 12.4 y 17.4 de las Directivas 24 y 23:

- Que las entidades intervinientes no tengan vocación de mercado, introduciendo aquí la regla cuantitativa prevista por el art. 12.4 de la Directiva: se presume la existencia de vocación de mercado cuando la entidad colaboradora realice en el mercado abierto un porcentaje igual o superior al 20\% de las actividades objeto de colaboración. Si no hay vocación de mercado, no puede falsearse la competencia que le es propia.

- Que el convenio establezca o desarrolle una cooperación entre las entidades participantes con la finalidad de garantizar que los servicios públicos que les incumben se prestan de modo que se logren los objetivos que tienen en común. Estos objetivos no tienen por qué ser idénticos. Basta con que sean complementarios.

- Que el desarrollo de la cooperación se guíe únicamente por consideraciones relacionadas con el interés público, lo que excluye cualquier idea de beneficio económico para una o ambas partes.

Este último criterio es decisivo para poder distinguir el convenio del contrato no por el objeto — tarea ardua, si no imposible, en muchos $\operatorname{casos}^{66}$-,

64 Cuyo origen se sitúa, como es sabido, en la Sentencia de 13 de enero de 2005 al Reino de España (asunto C-84/03), que declaró contraria a las directivas de contratación por excluir sin matices los convenios de colaboración del ámbito de aplicación de la Ley de Contratos de las Administraciones Públicas.

65 Véanse las sentencias Comisión contra Alemania, asunto C-480/06, Azienda Sanitaria Locale di Lecce, asunto C-159/11, Piepenbrock, asunto C386/11.

66 Piénsese que los convenios administrativos de cooperación interadministrativa en el que hay intercambio de prestaciones y cobertura de costes para la utilización conjunta de recursos (art. 48.3 Ley 40/2015) pueden reconducirse sin dificultad alguno de los objetos contractuales previstos en el CPV. En esto coincide también F. J. Villar Rojas, "Los convenios para la prestación conjunta de servicios...», op. cit. pág. 9, autor que, sin embargo, considera que estos convenios para la prestación conjunta de servicios se caracterizan precisamente por ser onerosos; interpretación de la onerosidad que puede ser correcta dogmáticamente, pero que a mi juicio veda el art. 2 de la Ley cuando dota de contenido positivo preciso el concepto de onerosidad. Por su parte, A. Huergo opina que «los convenios cuyo objeto coincide con el de un contrato público existen y, de hecho, la actual regulación de los convenios en la Ley de Régimen Jurídico del Sector Público se refiere a ellos de forma expresa y como uno de los principales ejemplos de aplicación de la figura. En este sentido, puede sorprender que la Ley parta de la idea de que los convenios con objeto contractual 
sino por su causa no onerosa, que debe interpretarse jurídicamente entre nosostros en los términos introducidos ahora en el art. 2 de la ley: «Se entenderá que un contrato tiene carácter oneroso en los casos en que el contratista obtenga algún tipo de beneficio económico, ya sea de forma directa o indirecta». Lo que excluye cualquier beneficio económico en este tipo de negocios jurídicos cooperativos $^{67}$. Y, al hacerlo, convenios y encargos se homologan entre sí, pues ambos negocios jurídicos comparten el régimen de compensación por coste real que ha pasado a caracterizar ahora el régimen básico de los medios propios (art. 32 Ley 9/2017). Una consecuencia clara de su pertenencia al género común de las operaciones de autoprovisión administrativa, que se caracteriza por excluir el margen de beneficio mercantil propio de la operativa de mercado ${ }^{68}$.

\section{LA PARTICIPACIÓN PRIVADA EN LAS PERSONIFICACIONES INSTRUMENTALES: GEOMETRÍA VARIABLE}

Otra de las novedades más destacadas de la Ley es el distinto régimen otorgado a la participación privada en personificaciones instrumentales que traban relaciones horizontales o verticales con otros poderes adjudicadores.

Frente a la permisión de colaboración horizontal entre entidades del sector público que incluyan participación privada, el legislador español prohíbe - aunque con excepciones, como inmediatamente veremos- la colaboración vertical con medios propios que tengan participación de capital privado. Y ello, a pesar de que la Directiva contemplase la posibilidad de excepcionar tal criterio en el art. 12.1.c) ${ }^{69}$.

no son admisibles, cuando desde 2009 se admite su existencia, aunque sometida a determinados requisitos». Cfr. op. cit., pág. 18.

67 El Consejo de Estado lo ha señalado así: «[...] no puedan calificarse como convenios de colaboración excluidos de la legislación de contratos las relaciones entre entidades públicas que puedan ser objeto de un contrato de naturaleza onerosa, pues la onerosidad es el único requisito que impone el artículo 2.1 del anteproyecto para calificar los contratos sujetos a su regulación. Este planteamiento deja sin contenido la exclusión e impide que los convenios sean la forma normal de relacionarse entre los entes públicos, lo cual debe ser ponderado». Cfr. Informe del Consejo de Estado, 1.116/2015, de 10 de marzo de 2016, sobre el anteproyecto de Ley, pág. 63.

Sobre esto, véase en particular la Sentencia de 11 de diciembre de 2014, asunto C-113/13, Azienda sanitaria locale.

69 «Que no exista participación directa de capital privado en la persona jurídica controlada, con la excepción de las formas de participación de capital privado sin capacidad de control mayoritario ni minoritario que estén impuestas por las disposiciones legales nacionales, de conformidad con los Tratados, y que no ejerzan una influencia decisiva sobre la persona juridica controlada». 
Este distinto régimen hará que los gestores giren su vista hacia la operativa horizontal (mediante convenio) antes que hacia la vertical, cuando se trate de autoprovisionarse con entidades de derecho privado en cuyo capital o dotación participe el sector privado (fundaciones públicas y sociedades públicas mixtas). Como ha señalado F. J. Villar Rojas, «nada se opone a esta fórmula» ${ }^{70}$. De hecho, el espaldarazo a las fórmulas horizontales van a suponer con toda probabilidad la extensión de lo que podríamos denominar "fórmulas mixtas» (combinatoria de convenio y encargo) de autoprovisión; unas fórmulas ya usadas normalmente por TRAGSA para montar su operativa con entidades locales que no poseen participación en su capital social. Tal operativa, amparada por el art. 2.4 del Real Decreto 1072/2010, de 20 de agosto, por el que se desarrolla el régimen jurídico de la Empresa de Transformación Agraria, Sociedad Anónima, y de sus filiales, consiste en que el Ministerio firma un convenio con la entidad local, y una vez hecha la cooperación horizontal, el Ministerio encarga a TRAGSA mediante cooperación vertical (encargo) las obras o servicios necesarios para su ejecución $\mathrm{n}^{71}$.

\section{EL DISTINTO RÉGIMEN DE RECURSO ESPECIAL}

Debe subrayarse también que el art. 44.2.e) de la Ley 9/2017 solo ha abierto explícitamente el recurso especial a los encargos que no cumplan con los requisitos legales, pero no a los convenios interadministrativos o las encomiendas de gestión, lo cual es simplemente incoherente con el efecto útil de las directivas, tal y como ya se ha reconocido por algunos tribunales administrativos de contratos y por el TJUE. Este distinto régimen de garantías llevará también probablemente a que los operadores opten por instrumentos horizontales antes que verticales.

70 Cfr. «Los contratos para la prestación conjunta de servicios públicos locales», op. cit., pág. 13.

71 Dice así el art. 2.4 mencionado: «TRAGSA y sus filiales, en virtud de su condición de medios propios instrumentales, podrán ser aportadas por la Administración General del Estado o las comunidades autónomas en sus relaciones de cooperación con otras Administraciones o sujetos jurídicopúblicos. Esta relación de cooperación se instrumentará a través de un convenio de colaboración entre las Administraciones o sujetos jurídico-públicos interesados, que especificará el interés público común que justifique la suscripción del convenio, las actuaciones a desarrollar, y la aportación de cada una de las partes. El Estado o la comunidad autónoma comunicarán a TRAGSA y a sus filiales la suscripción de estos convenios y le encomendarán las actuaciones necesarias para la ejecución de lo dispuesto en los mismos». 


\section{LA HIPERTROFIA DEL ANTIGUO 24.6 TRLCSP: ARTíCULOS 31 A 33, LEY $9 / 2017$}

Además de lo previsto en la sección de negocios excluidos, las técnicas de autoprovisión del sector público se incorporan parcialmente ahora en el capítulo de la Ley 9/2017 destinado a la «racionalidad y consistencia de la contratación en el sector público", que es donde la nueva LCSP desarrolla el afán comunitario de incorporar y regular distintas técnicas no contractuales de autoprovisión administrativa, mediante una suerte de hipertrofia del antiguo art. 24.6 TRCLSP que no acaba de encajar bien con la arquitectura de tales técnicas.

En este capítulo aparecen ahora inventariadas los que en la terminología comunitaria se consideran mecanismos de cooperación pública horizontal y vertical. Aunque el art. 31 no incluye la ejecución de obras por administración, pues la denominada «ejecución directa de prestaciones por la Administración Pública con la colaboración de empresarios particulares o a través de medios propios no personificados» constituye el objeto del art. precedente, el 30, que desarrolla las dos modalidades de ejecución con servicios propios — esto es, integrados en la estructura orgánica administrativa y no segregados mediante personificación independiente- o bien con colaboración de empresarios particulares.

La regulación, que sigue conservando su carácter no básico ${ }^{72}$, contiene dos novedades de interés: desaparece el umbral máximo de ejecución directa de obras, e incorpora una relevante regla de racionalización de la contratación, que complementa lo previsto por el art. $28^{73}$. Ahora bien, el hecho de ser un precepto no básico implica que solo es aplicable para la Administración General del Estado, abriendo en consecuencia las puertas a que los legisladores de las comunidades autónomas incluyan sus propias regulaciones de la ejecución

72 Tal y como hacía la disposición final segunda del TRLCSP de 2011, que consideraba no básico el art. 24 en sus apdos. 1 a 5, la disposición final primera de la LCSP no considera básico el art. 30 .

73 El párrafo tercero del precepto establece la siguiente regla de racionalización: «La prestación de servicios se realizará normalmente por la propia Administración por sus propios medios». Y «cuando carezca de medios suficientes» — cuestión que habrá que motivar en el expediente de contratación, de conformidad con los arts. 28 y 116 -, se podrá acudir a la contratación externa, de conformidad con lo establecido por los arts. 306 y siguientes. De ello se deriva que, cuanto más objetiva sea la carencia de medios, más fácil será motivar la externalización contractual; y cuantos más medios tenga a su disposición la Administración, más tendrá que esforzarse el gestor para motivar su externalización. 
por Administración, en particular el desarrollo de lo que consideren a estos efectos sus "propios medios».

Por su parte, el art. 31 constituye lo que podemos denominar un precepto-esquema: traza el mapa de las posibles formas de cooperación pública, sin contenido contractual, entre las entidades pertenecientes al sector público. Se trata de un precepto paradójico, que no debería figurar en la ley de contratos, sino probablemente en la Ley 40/2015, dado que desarrolla y complementa lo previsto por el art. 6, que precisamente excluye estos negocios cooperativos del ámbito de la LCSP. Para cooperar en el cumplimiento de sus respectivas misiones de servicio público, en el uso de su potestad de autoorganización, las entidades pertenecientes al sector público pueden cooperar de TRES maneras:

a) Mediante sistemas de cooperación vertical consistentes en el uso de medios propios personificados en el sentido y con los límites establecidos en el art. 32 para los poderes adjudicadores, y en el art. 33 para los entes del sector público que no tengan la consideración de poder adjudicador, mediante el oportuno acuerdo de encargo.

Se establecen dos regímenes en función de si el ente del sector público encomendante recibe o no la calificación de poder adjudicador, calificación que dependerá del juicio singular $-\mathrm{y}$ no pocas veces difícil- de contraste de los criterios previstos a tal efecto por el art. 3 para la inclusión en el sector público (art. 3.1) y la exclusión de la noción de poder adjudicador (art. 3.3).

b) Mediante sistemas de cooperación horizontal entre entidades pertenecientes al sector público, previa celebración de los correspondientes convenios, en las condiciones y con los límites que se establecen en el apdo. 1 del art. 6, que ya hemos expuesto.

c) Mediante realización conjunta de contrataciones esporádicas. Se trata de un nuevo contenido del precepto, introducido mediante enmienda en el Congreso de los Diputados ${ }^{74}$, que traspone la previsión del art. 38 de la Directiva 2014/24 sobre contratación conjunta esporádica. Sin embargo, es de notar que no se especifica cómo se

74 En concreto, la enmienda núm. 38, del G. P. Confederal de Unidos Podemos-En Comú Podem-En Marea, cuya justificación es la siguiente: «Se trata de trasponer de una forma más completa y adecuada el artículo 38 de la Directiva 2014/24, del Parlamento Europeo y del Consejo, sobre contratación pública, para que quede más y mejor clarificada la posibilidad de la contratación conjunta esporádica, lo que sin duda conviene fomentar especialmente entre Entidades Locales, pero también entre las demás entidades del sector público, en aras de una mayor eficiencia en la contratación. Para ello es necesario también numerar el artículo y dividirlo en tres apartados». 
debe instrumentar jurídicamente estas contrataciones esporádicas, aunque todo apunta a la necesidad de un convenio o acuerdo de colaboración $^{75}$.

Como mapa de navegación sobre esa complejidad, podemos manejar el siguiente cuadro de equivalencias:

\begin{tabular}{|c|c|c|c|}
\hline TÉCNICA & $\begin{array}{c}\text { DIRECTIVAS } \\
2014 / 24 \text { y } 2014 / 23\end{array}$ & LCSP & $\begin{array}{c}\text { INSTRUMENTO } \\
\text { JURÍDICO }\end{array}$ \\
\hline $\begin{array}{l}\text { Ejecución directa por } \\
\text { la Administración }\end{array}$ & & Art. 30 & $\begin{array}{c}\text { Resolución de } \\
\text { autorización } \\
\text { (art. 30.5) }\end{array}$ \\
\hline $\begin{array}{l}\text { Cooperación vertical } \\
\text { descendente bilateral }\end{array}$ & Art. $12.1,17.1$ & $\begin{array}{l}\text { Art. } 32 \text { (poderes } \\
\text { adjudicadores) } \\
\text { Art. } 33 \text { (no poderes } \\
\text { adjudicadores) }\end{array}$ & $\begin{array}{c}\text { Acuerdo de encargo } \\
\text { (art. } 30.5 \text { y } 31.1 . \mathrm{a}) \\
\text { in fine }\end{array}$ \\
\hline $\begin{array}{l}\text { Cooperación vertical } \\
\text { ascendente bilateral }\end{array}$ & Art.12.2, 17.2 & Art. 32.3 & $\begin{array}{c}\text { Acuerdo de encargo } \\
\text { (art. } 30.5 \text { y } 31.1 . \mathrm{a}) \\
\text { in fine }\end{array}$ \\
\hline $\begin{array}{l}\text { Cooperación vertical } \\
\text { con control conjunto }\end{array}$ & Art. $12.3,17.3$ & Art. 32.6 & $\begin{array}{c}\text { Acuerdo de encargo } \\
\text { (art. } 30.5 \text { y 31.1.a) } \\
\text { in fine }\end{array}$ \\
\hline $\begin{array}{c}\text { Cooperación } \\
\text { horizontal }\end{array}$ & Art. $12.4,17.4$ & Art. 6, art. 31.1.b & $\begin{array}{l}\text { Convenios } \\
\text { (art. 31.1.b) }\end{array}$ \\
\hline $\begin{array}{c}\text { Contrataciones } \\
\text { conjuntas esporádicas }\end{array}$ & $\begin{array}{l}\text { Considerando 71, art. } \\
38 \text { Directiva 2014/24 }\end{array}$ & Art. 31.3 & ¿Convenio? \\
\hline
\end{tabular}

75 Valgan dos ejemplos sectoriales. El art. 56 de la Ley gallega 1/2015, de calidad de los servicios públicos y de la buena administración, regula los denominados «convenios de colaboración para la cogestión", para el caso de aquellos servicios públicos que sean prestados mancomunadamente por dos o más administraciones. Por su parte, el art. 15 de la Ley gallega 14/2013, de racionalización del sector público autonómico, regula con detalle los «acuerdos de colaboración o cooperación para la financiación conjunta de contratos para la satisfacción de una finalidad común». 
Un esquema más visual y dinámico podría ser el siguiente:

Cooperación horizontal

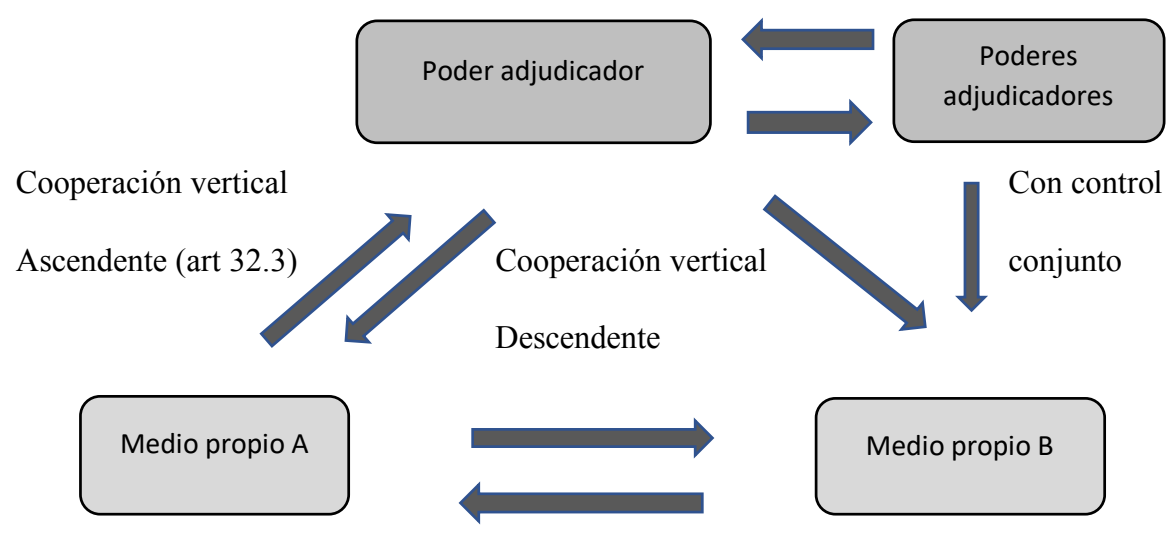

Cooperación horizontal (art. 32.3)

A partir de aquí, la Ley 9/2017 desgrana una regulación mucho más densa respecto de la operativa vertical, en consonancia con las novedades incorporadas por los arts. 12 y 17 de las directivas.

Los arts. 32 y 33, en particular, contienen múltiples acotaciones aplicables a los encargos a medios propios personificados por parte de poderes adjudicadores (art. 32) y de entidades del sector público que no sean poder adjudicador (art. 33) ${ }^{76}$. Esas acotaciones son de naturaleza básica, dictadas al amparo del art. $1491.1 .18^{\mathrm{o} 77}$, y se aplicarían a todo el sector público.

Pero la LCSP ha hecho, además, otra cosa, aunque sea mediante una técnica legislativa harto confusa: la disposición final segunda de la Ley fija en su párrafo tercero la siguiente regla: «En relación con el régimen jurídico de los medios propios personificados, en lo no previsto en la presente Ley, resultará de aplicación lo establecido en la Ley 40/2015 de 1 de octubre, de Régimen Jurídico del Sector Público». Dado que esta disposición final segunda tiene carácter básico, de conformidad con la disposición final primera, todo indica

76 Para un análisis más sistemático de las novedades introducidas en la Ley 9/2017, me remito a mi trabajo (2018), «Los encargos a medios propios e instrumentales. ¿Hacia un nuevo comienzo?», en J. M. Gimeno Feliú, Comentarios a la Ley 9/2017, de contratos del sector público (págs. 369-410), Cizur Menor: Thomson Reuters Aranzadi.

77 Véase la disposicion final primera (títulos competenciales). Sin embargo, debe matizarse que esta misma disposición final excluye de naturaleza básica la letra c) del apdo. 5 del art. 32. 
que el legislador ha querido convertir sobrevenidamente en básico — por tanto, de aplicación general para todas las administraciones-, el contenido del art. 86 de la Ley 40/2015, incluidas las obligaciones de control de eficiencia en la creación y funcionamiento de medios propios y de instalación de "collar» en sus denominaciones.

Como puede observarse, la ley se ha preocupado de aumentar los filtros y requisitos de idoneidad de los medios propios, tanto sobre la propia atribución de tal condición como sobre la justificación en los encargos singulares. En este sentido, la Ley 9/2017 establece una serie de nuevas obligaciones de verificación y publicidad (art. 32.2.d), art. 32.6) en ambos planos, que se ańaden a las previstas por el art. 8 de la Ley 19/2013 (que atañe a la publicidad de las encomiendas en los portales de transparencia). Por expresarlo brevemente: se ha mejorado la eficacia del sistema legal de "levantamiento del velo" de los encargos. Aunque ello merezca el aplauso, de nuevo la técnica legislativa opta por una superposición — poco diáfana— de controles sobre los encargos, más que por una regulación sistemática en un cuerpo legal especial.

\section{LA ENIGMÁTICA REGULACIÓN DE LA GESTIÓN DE SERVICIOS PÚBLICOS MEDIANTE PERSONIFICACIONES INSTRUMENTALES}

Una de las más difíciles cuestiones que nos deja la Ley 9/2017 es el régimen de la gestión directa de los servicios públicos mediante personificaciones instrumentales. Una cuestión que ha sufrido una amplia transformación en la Ley 9/2017 como consecuencia del impacto de la Directiva 23/2014, y como consecuencia de la explícita admisión de encargos a medios propios para cualquier modalidad contractual típica, incluidas las concesionales. Veamos los términos del problema.

Hasta el 9 de marzo de 2018 seguirá en vigor la remisión prevista en el art. 8.2 TRLCSP, conforme a la cual: «Las disposiciones de esta Ley referidas a este contrato no serán aplicables a los supuestos en que la gestión del servicio público se efectúe mediante la creación de entidades de derecho público destinadas a este fin, ni a aquellos en que la misma se atribuya a una sociedad de derecho privado cuyo capital sea, en su totalidad, de titularidad pública». Remisión que reenviaba a las formas de gestión directa previstas por la LBRL en su art. 85.2.

A partir del 9 de marzo, sin embargo, esta regla de remisión de la gestión directa mediante creación de entidades instrumentales se pierde en el piélago montado por el legislador básico de contratos para encastrar en nuestro derecho el nuevo contrato típico de concesión de servicios. Ahora, los contratos de gestión de servicios públicos se reconducen o bien a la concesión de servicios (cuando exista transmisión del riesgo operacional), o bien a los contratos de servicios; 
en especial, a ese trasunto del contrato de gestión de servicios públicos que se contiene en el art. 312 bajo la rúbrica "especialidades de los contratos de servicios que conlleven prestaciones directas a favor de la ciudadanía» ${ }^{78}$. De la regla del art. 8.2, la Ley 9/2017 apenas ha conservado un vestigio de su contenido a la hora de establecer una excepción a la regla limitativa de la subcontratación de los medios propios al $50 \%(\text { art. 32.7 })^{79}$.

El art. 32.1, por su parte, ha abierto la posibilidad de que sea objeto de encargo a medios propios personificados todo tipo de contratos ${ }^{80}$, incluidos los contratos típicos de gestión indirecta de servicios públicos, tanto en la modalidad de contrato de servicios como en las modalidades concesionales. Algo que se permite explícitamente por el art. 17 de la Directiva 23.

El problema, sin embargo, reside en que el art. 32 de la Ley 9/2017 ha establecido con carácter general la obligación de que los encargos a medios propios se compensen con tarifas ajustadas al coste efectivo, lo que resulta en principio incompatible con el riesgo operacional que caracteriza estas

78 Un buen estado de la cuestión puede verse en el trabajo de J. C. Laguna de Paz (2017), "Los contratos administrativos de concesión de servicios y de servicios a los ciudadanos», Revista de Administración Pública, 204, págs. 41-68.

79 «El importe de las prestaciones parciales que el medio propio pueda contratar con terceros no excederá del 50 por ciento de la cuantía del encargo.

No será aplicable lo establecido en esta letra a los contratos de obras que celebren los medios propios a los que se les haya encargado una concesión, ya sea de obras o de servicios. Igualmente, no será de aplicación en los supuestos en los que la gestión del servicio público se efectúe mediante la creación de entidades de derecho público destinadas a este fin, ni a aquellos en que la misma se atribuya a una sociedad de derecho privado cuyo capital sea, en su totalidad, de titularidad pública».

80 Recuérdese el tenor del art. 32.1: «Los poderes adjudicadores podrán organizarse ejecutando de manera directa prestaciones propias de los contratos de obras, suministros, servicios, concesión de obras y concesión de servicios, a cambio de una compensación tarifaria, valiéndose de otra persona jurídica distinta a ellos, ya sea de derecho público o de derecho privado, previo encargo a esta, con sujeción a lo dispuesto en este artículo, siempre y cuando la persona jurídica que utilicen merezca la calificación jurídica de medio propio personificado respecto de ellos de conformidad con lo dispuesto en los tres apartados siguientes, y sin perjuicio de los requisitos establecidos para los medios propios del ámbito estatal en la Ley 40/2015, de 1 de octubre, de Régimen Jurídico del Sector Público». El art. 25 del Proyecto de Ley de sectores excluidos también permite el encargo a medios propios personificados de contratos de concesión de obras o servicios, «a cambio de una compensación tarifaria, valiéndose de otra persona jurídica distinta a ellos, ya sea de derecho público o de derecho privado, previo encargo a esta, con sujeción a lo dispuesto en el artículo 32 de la Ley de Contratos del Sector Público». 
figuras contractuales ${ }^{81}$. Lo único seguro en este ámbito son los supuestos contemplados por la disposición adicional vigésima segunda de la Ley 9/2017, conforme a la cual las concesiones de obras y de servicios podrán adjudicarse directamente a una sociedad de economía mixta en la que concurra mayoritariamente capital público con capital privado, siempre que la elección del socio privado se haya efectuado de conformidad con las normas establecidas en esta ley para la adjudicación del contrato cuya ejecución constituya su objeto, y siempre que no se introduzcan modificaciones en el objeto y las condiciones del contrato que se tuvieron en cuenta en la selección del socio privado ${ }^{82}$. Previsión que sigue el criterio recogido por el Tribunal de Justicia de la Unión Europea en su Sentencia de 15 de octubre de 2009 en el asunto C-196/08, Acoset $S p A$, y en la Comunicación Interpretativa de la Comisión Europea relativa a la aplicación del derecho comunitario en materia de contratación pública y concesiones a la colaboración público-privada institucionalizada de 5 de febrero de 2008, pero que no acaba de encajar limpiamente — más bien al contrario, a mi entender- dentro de la precaria arquitectura que el legislador estatal ha diseñado en estas materias.

\section{LA POSITIVACIÓN DE LA AUTOPROVISIÓN ADMINISTRATIVA EN EL DERECHO AUTONÓMICO DE GALICIA}

El derecho autonómico de Galicia ha sido el primero en incorporar el concepto jurídico de autoprovisión administrativa, desarrollando - pocos meses antes de la aprobación de las directivas de 2014 — una lectura más ajustada de las posibilidades ofrecidas por el derecho comunitario.

Su sistemática es la siguiente.

Mediante su Ley 16/2010, de 17 de diciembre, de organización y funcionamiento de la administración general y del sector público autonómico,

81 De hecho, el considerando 17 de la Directiva 23 establece claramente que: «La presente Directiva no debe aplicarse a los contratos que no conlleven pagos al contratista y en los que este reciba su retribución de acuerdo con tarifas reglamentadas calculadas de manera que cubran la totalidad de los costes e inversiones que este haya soportado para prestar el servicio».

82 En opinión de J. C. Laguna de Paz (2017): «La admisibilidad de la adjudicación directa en estos casos se justifica por razones de economía procedimental. Los principios que trata de salvaguardar la normativa contractual pública se observaron ya aguas arriba, en el momento de elección del socio privado, por lo que no tendría sentido obligar a la Administración a convocar un nuevo procedimiento de selección para adjudicar el contrato" (cfr. op. cit., pág. 60). 
Galicia aprobó su propia normativa legal sobre sus medios propios y servicios técnicos, todavía vigente.

En esta ley se distinguen tres tipos de negocios jurídicos de cooperación dentro del sector público autonómico gallego: las encomiendas de gestión intrasubjetiva (entre órganos de la misma administración autonómica, art. 8), que operan conforme al esquema autorización+acuerdo; las encomiendas de gestión intersubjetiva (entre distintas administraciones, art. 9), que se canalizan mediante convenios interadministrativos de colaboración; finalmente, las encomiendas de gestión a entidades de derecho privado que tengan la condición de medio propio o servicio técnico (art. 10), cuyos detalles se desarrollan con pormenor en los arts. 47 a 50, en los que se definen qué entidades tienen la condición de medios propios y servicios técnicos de la comunidad autóno$\mathrm{ma}^{83}$ su control, organización de los trabajos, tarifas, anticipos y gastos, etc.

Además de lo anterior, nuestra Ley 14/2013, de 26 de diciembre, de racionalización del sector público autonómico ${ }^{84}$, ha apostado con claridad por desarrollar las técnicas de cooperación administrativa, encabezándolas con el art. 8, que se rubrica como «Autoprovisión de bienes y de servicios dentro del propio sector público», e introduce las siguientes reglas de racionalización de la provisión de bienes y servicios del sector público autonómico gallego:

1. La Administración general de la comunidad autónoma y las entidades instrumentales del sector público, con la finalidad del uso eficiente de los recursos públicos existentes, realizarán las tareas de interés público que les corresponden con los medios personales, técnicos, materiales y de cualquier otro tipo de los que disponga el sector público autonómico.

2. A los efectos indicados en el apartado anterior, cuando los medios de los que dispongan resulten insuficientes para el cumplimiento y realización de sus fines institucionales, acudirán con preferencia a la cooperación, colaboración y asistencia de otros órganos de la Administración general de la comunidad autónoma o de otras entidades

83 «A los efectos previstos en el artículo 4. ${ }^{\circ}$ 1.n) y 24.6 de la Ley 30/2007, de 30 de octubre, de contratos del sector público, todas las entidades instrumentales determinadas en el artículo 45 tienen la consideración de medios propios y servicios técnicos de aquellos poderes adjudicadores para los cuales realicen la parte esencial de su actividad cuando éstos ejerzan sobre aquéllos un control análogo al que pueden ejercer sobre sus propios servicios. Si se trata de sociedades, además, la totalidad de su capital tendrá que ser de titularidad pública».

84 Véase Diario Oficial de Galicia, 17, de 27 de enero de 2014. 
del sector público autonómico que sí dispongan de los medios de los que precisan.

3. A estos efectos se elaborarán, en los términos previstos en el artículo siguiente, catálogos de medios y prestaciones susceptibles de ser objeto de cooperación, colaboración y asistencia en el ámbito interno del sector público autonómico.

4. Para los medios y prestaciones incluidos en el catálogo, solo podrá acudirse a la contratación externa cuando la autoprovisión no resulte viable, por no poder ser cumplidamente satisfechas por otros órganos o entidades instrumentales del sector público las necesidades que se pretenden cubrir, mediante alguno de los procedimientos de colaboración indicados en la presente ley, por la insuficiencia, carencia o inadecuación de los medios de los que dispongan.

Estos aspectos deberán ser objeto de justificación en los expedientes de contratación en los términos previstos en el art. 33 de la presente ley.

5. En cualquier caso, si así está previsto en el catálogo, el órgano o entidad a la que habría correspondido la asunción de las tareas que serán objeto de contratación externa deberá supervisar y prestar asistencia en el proceso de contratación y en la ejecución de las prestaciones para velar por la coordinación y asegurarse de que no se generen duplicidades.

Como puede observarse, el concepto de autoprovisión se construye como una regla de racionalización que apuesta por el aprovechamiento preferente de los recursos públicos (materiales, personales y de cualquier otro tipo) de que disponga el conjunto del sector público autonómico, antes del recurso a la externalización contractual ${ }^{85}$. Ese aprovechamiento preferente se convierte en obligatorio cuando la prestación o medio se incluya en el «catálogo de medios y prestaciones susceptibles de ser objeto de cooperación, colaboración y asistencia en el ámbito interno del sector público autonómico». Tal catálogo ha sido aprobado por Resolución de 17 de noviembre de 2014, de la Secretaría

85 Como afirma la Xunta de Galicia en su Guía de la colaboración público-pública de la Comunidad Autónoma de Galicia, de junio de 2015: «El principio de autoprovisión significa que el sector público autonómico realizará sus funciones: 1) Con los medios de que disponga; 2) Cuando estos no sean suficientes, recurrirá al sector público autonómico (colaboración público-pública). Para este fin se crea el catálogo de medios y prestaciones que facilitará la identificación de aquellos medios y prestaciones susceptibles de ser prestados por la vía de la autoprovisión. 3) Sólo en último término recurrirá al mercado (contratos públicos)». 
General Técnica de la Consellería de Presidencia, Administraciones Públicas y Justicia, que ha hecho público el «Acuerdo del Consello de la Xunta de 18 de septiembre de 2014, por el que se aprueba el Catálogo de medios y prestaciones susceptible de autoprovisión y se toma razón de los suministros, obras, servicios y cualquier otra prestación susceptible de contratación centralizada» ${ }^{86}$. En él se recogen servicios como las inversiones y matenimiento en telecomunicaciones, servicios de administración electrónica, de evaluación de resultados, de gestión de emergencias, de cesión de instalaciones, de informes, formación y organización de actividades, asistencia jurídica a entidades del sector público autonómico, estudios competenciales sobre producción normativa del Estado y otras comunidades autónomas, auditoría de cuentas, formación, recogida y análisis de datos estadísticos, servicio técnico en infraestructuras, servicios de cartografía y análisis geográfico, redacción de planes y proyectos sectoriales, redacción de proyectos de expropiación, asesoramiento y gestión en materia de instrumentos financieros, servicios de análisis de aguas, $\mathrm{I}+\mathrm{D}+\mathrm{i}$ en el ámbito agrario y forestal y servicios de análisis del medio marino.

\section{PROPUESTA DE LEGE FERENDA}

Con independencia de la sistematización doctrinal que de ellas pueda realizarse, lo cierto es que, en el actual grado de desarrollo de nuestro derecho público, la dispersión de perspectivas reguladoras de la autoprovisión en tres grupos normativos (el de la organización, contratos y defensa de la compe-

86 Véase $D O G, 7$, de 13 de enero de 2015. Posteriormente, la reciente Ley 4/2016, de 4 de abril, de ordenación de la asistencia jurídica de la Administración General de la Comunidad Autónoma de Galicia y de su sector público (DOG, 69, de 12 de abril) ha incorporado en su art. 5 una regulación sobre "Autoprovisión dentro del sector público y contratos de asistencia jurídica con medios externos». Como curiosidad, señalaré que gracias a una enmienda parlamentaria impulsada por quien esto escribe desde la Secretaría General de la Universidade da Coruña, se ha incluido en el párrafo segundo de este precepto la referencia a las universidades públicas gallegas: «Para las prestaciones de asistencia jurídica sólo podrá acudirse a la contratación externa cuando la autoprovisión no resulte viable, por no poder ser adecuadamente satisfechas por la Asesoría Jurídica General las necesidades que se pretenden cubrir, por la insuficiencia, carencia o inadecuación de los medios de que dispone, en los términos establecidos en la Ley 14/2013, de 26 de diciembre, de racionalización del sector público autonómico. A estos efectos, se entenderá por asistencia jurídica con medios externos los servicios de tal carácter prestados por universidades públicas, empresas consultoras o abogados/as en ejercicio a la Administración general de la Comunidad Autónoma de Galicia o a su sector público». 
tencia), y la focalización dogmático-formal sobre las categorías de convenio, encomienda de gestión y encargo, produce un escenario asistemático de inseguridad jurídica nada propicia para el correcto desarrollo y control jurídico de estas técnicas.

Títulos competenciales de distinta naturaleza y relevancia se entremezclan y confunden: leyes básicas de contratación que entran en temas organizativos; leyes autonómicas de contratación que desarrollan directamente el derecho comunitario; leyes básicas de organización administrativa que regulan las relaciones de colaboración (convenios), pero no regulan los medios propios en el conjunto del sector público; leyes autonómicas de organización administrativa que desarrollan minuciosamente la organización y operativa de los medios propios... Al mismo tiempo, la ausencia de una regulación de conjunto sobre estas técnicas provoca una escasa densidad normativa de naturaleza básica, hoy apenas acantonada en el plano contractual, propiciando así una fragmentación de soluciones en los derechos autonómicos. Esto ha merecido la crítica del Tribunal de Cuentas, que ha reclamado un marco jurídico común regulador del régimen de encomiendas a medios propios.

Pero la recomendación del Tribunal de Cuentas se queda corta: no solo es necesaria una ley especial sobre los encargos; a nuestro juicio, dada la comprensión común de la autoprovisión que acometen las directivas de 2014, la técnica normativa más correcta debería haber consistido en considerar todas las formas de cooperación, verticales u horizontales, como negocios excluidos, extracontractuales, remitiendo a continuación la regulación sustantiva de estas figuras de autoprovisión a sus normas propias o especiales: bien a una disposición adicional de modificación de la Ley 40/2015, en la que se introdujese un capítulo específico destinado a la regulación básica de estas técnicas, o bien a una ley básica específica, dictada al amparo del art. 149.1.18 .

En mi opinión, esta regulación básica, en uno u otro formato, debería abordar sistemáticamente una reordenación de las técnicas de las encomiendas de gestión, convenios y encargos, reconduciéndolas a dos tipologías (encargos y convenios de colaboración) como formas operativas de plasmación de la autoprovisión administrativa. La encomienda de gestión debería suprimirse sin más: sería lo más coherente con Europa y lo más seguro para los operadores jurídicos internos.

En definitiva, la política jurídica más segura y coherente con la naturaleza compleja de los medios propios sería la promulgación de una ley básica específica sobre la autoprovisión administrativa en el conjunto del sector público español, mediante la que se pudiesen abordar equilibradamente, en un único texto, sus distintas perspectivas ontológicas.

En este empeño, es esencial regular la autoprovisión como un principio general de racionalización de funcionamiento del sector público, caracterizado 
por su funcionalidad y vinculación al servicio objetivo de los intereses generales (art. $103 \mathrm{CE}$ ), así como el uso eficiente y equitativo de los recursos públicos (art. 31.2 CE). La autoprovisión debe dejar de considerarse una anomalía o una excepción. Tampoco debe regularse como una simple opción discrecional, tal y como hoy se deduce de los arts. 31 y 32 de la Ley 9/2017. Es, sencillamente, la primera opción, coherente con el hecho de que el recurso a la externalización contractual debe motivarse en los términos del art. 28 de la Ley 9/2017. Hemos visto que el derecho autonómico gallego ya ha introducido ese supraconcepto de autoprovisión administrativa en una ley en vigor. Me parece plausible extender la utilización de este concepto al ámbito básico, como pivote alrededor del cual giren las distintas modalidades técnicas de satisfacción de las necesidades de interés general dentro del propio sector público. Pero mientras el legislador básico no asuma este empeño, a buen seguro los legisladores autonómicos tendrán la oportunidad de hacerlo, en ejercicio de sus títulos competenciales de desarrollo legislativo de la normativa básica estatal configurada por las Leyes 40/2015 y 9/2017. Los desajustes de la Ley 9/2017 a buen seguro invitarán a ello. 
